\title{
Chapter 13 \\ The Conflict Between Pteropodid Bats \\ and Fruit Growers: Species, Legislation and Mitigation
}

\author{
Sheema Abdul Aziz, Kevin J. Olival, Sara Bumrungsri, \\ Greg C. Richards and Paul A. Racey
}

\begin{abstract}
Pteropodid bats damage a wide range of fruit crops, exacerbated by continuing loss of their natural food as forests are cleared. In some countries where such damage occurs, bats are not legally protected. In others, as a result of pressure from fruit growers, legal protection is either not implemented or overridden by legislation specifically allowing the killing of bats. Lethal control is generally ineffective and often carried out with shotguns making it an animal welfare issue, as many more animals are injured or orphaned than are killed. Here, we review the literature and current state of the conflict between fruit growers and pteropodids and describe a wide range of potential mitigation techniques. We compile an extensive list of bats and the fruit crops on which they feed where this has resulted in conflicts, or could lead to conflict, with fruit growers. We also discuss the legal status of bats in some countries where such conflicts occur. We found the most effective means of preventing bat damage to crops is the use of fixed nets (that generally prevent entanglement) covering a whole orchard. Netting individual trees, or fruit panicles, using small net bags, is also effective. Management methods that assist netting include pruning to maintain low stature of trees. These
\end{abstract}

\author{
S.A. Aziz $(\bowtie)$ \\ Rimba, Muséum National d'Histoire Naturelle, Paris, France \\ e-mail: sheema.abdulaziz@gmail.com \\ K.J. Olival \\ EcoHealth Alliance, New York, USA \\ e-mail: olival@ecohealthalliance.org \\ S. Bumrungsri \\ Department of Biology, Prince of Songkla University, Songkhla, Thailand \\ e-mail: sarabumrungsri@gmail.com \\ G.C. Richards \\ Bat Fauna Consultant, Canberra, Australia \\ e-mail: batman3812@bigpond.com


exclusion techniques are the best management options considering both conservation and public health issues. Although lights, sonic and ultrasonic noises, noxious smells and tastes have been used to deter bats from eating fruit, there have been no large-scale systematic trials of their effectiveness. Nevertheless, broadcasting the sound of discharging shotguns followed by the sound of wounded bats has proved effective in Australia. The use of decoy fruit trees is the least investigated method of mitigation and requires detailed knowledge of the natural diet of the bat species involved. The few studies of dietary preferences undertaken to date suggest that bats prefer non-commercial fruit when it is available, and we highlight this as an area for future research.

\subsection{Introduction}

The Old World bat family Pteropodidae is distributed throughout the tropics and subtropics of Australasia, Africa and Oceania (Marshall 1983; Mickleburgh et al. 1992). It comprises 196 species (Simmons 2005) that feed primarily on fruit, flowers (nectar, pollen, petals and bracts) and leaves of at least 188 plant genera from 64 families (Lobova et al. 2009; Fleming and Kress 2011), although some species have also been recorded eating insects (e.g. Clulow and Blundell 2011; Scanlon et al. 2013). Fujita (1988) and Fujita and Tuttle (1991) used the term 'flying foxes' to refer to all bats in the family Pteropodidae, but we restrict this term to the 70 species in the genera Pteropus and Acerodon (IUCN 2014), following the definition outlined by Kingston (2010), and use the term 'fruit bats' for the remainder.

Although bat-plant interactions were first recorded in 1772, it is now known that coevolution has shaped these complex interrelationships over millennia, producing bat-flower and bat-fruit syndromes (Marshall 1983; Fleming et al. 2009). This phytophagous diet results in valuable ecosystem services of pollination and seed dispersal (Kunz et al. 2011). Pteropodid bats are responsible for propagating at least 289 species of plants, of which 186 provide economically important resources and products including fruits, drinks, foods, ornamental plants, timbers, fibres, tannins, dyes, medicines, and animal fodder (Fujita and Tuttle 1991; Lobova et al. 2009). In addition, large populations of flying foxes are necessary to maintain the health of Old World tropical forests (Fujita and Tuttle 1991; Nyhagen et al. 2005; McConkey and Drake 2006). Such healthy functioning ecosystems ultimately provide humans with additional benefits such as climate regulation, nutrient cycling, water filtration, and erosion control (Kunz et al. 2011).

\footnotetext{
P.A. Racey

Centre for Ecology and Conservation, University of Exeter, Cornwall Campus,

Penryn, Cornwall, UK

e-mail: p.a.racey@exeter.ac.uk
}

S.A. Aziz

University of Nottingham Malaysia Campus, Semenyih, Malaysia 
Dependence on plant materials has also led to a long history of interactions between these bats and humans, particularly at shared food resources. Flying foxes with striped faces are depicted in aboriginal cave paintings in Kimberley, Australia, attributed to the Bradshaw people, between 17,000 and 60,000 years ago. Whether they brought such stripe-faced bats to the area or idolised the bat pollinator of a favoured tree, the baobab, in their drawings, is unknown. Genetic studies showed that baobab seeds were brought on their journey from Ethiopia to Australia, as an important provider of food, nutrients and building materials. This ancient rock art may be the first human recognition of the ecosystem services of pteropodids (Richards et al. 2012).

Despite the documented benefits of bats, negative attitudes towards them persist among the general public (Marshall 1983; Fujita and Tuttle 1991; Kunz et al. 2011). Pteropodid bats, in particular flying foxes, are frequently shot, persecuted and even legally culled as agricultural pests (Bumrungsri et al. 2009; Epstein et al. 2009). In Thailand, for example, farmers of durian (Durio zibethinus) set nets to catch the dawn bat (Eonycteris spelaea) visiting their trees when in flower and leave the bats to die, because they see that flowers fall after bat visits and conclude that bats have destroyed them (S. Bumrungsri, unpublished). In fact, the flowers fall naturally after the bats have pollinated them, but unhelpful misconceptions such as this exacerbate the conflict between bats and humans. In addition, pteropodid bats are hunted intensively for food and medicinal uses (including commercial trade), leading to severe declines throughout their range (Epstein et al. 2009; Mickleburgh et al. 2009; Harrison et al. 2011). Estimates based on current deforestation rates in Southeast Asia project that many pteropodids may become globally extinct by the end of this century (Lane et al. 2006), with flying foxes being of particular concern in Southeast Asia due to intense hunting pressure (Struebig et al. 2007; Meyer et al. in press). The Old World Fruit Bat Action Plan (Mickleburgh et al. 1992) helped stimulate research on pteropodids but is now out of date and is being revised. The conservation status of these bats has worsened since the plan was published, and a quarter of all species are now endangered (IUCN 2014).

Here, we review the current state of knowledge regarding human-pteropodid interactions by geographic region, legal policies affecting pteropodid bats, and methods of mitigating the damage they cause to fruit crops.

\subsection{The Extent of Feeding by Bats on Fruit Crops and Its Implications}

The fruit crops which bats have been reported to damage are listed in Table 13.1.

\subsubsection{The Mediterranean}

Madkour (1977), writing about the Egyptian fruit bat (Rousettus aegyptiacus) in Egypt, stated that it was 'a highly dangerous fruit pest' and that 'its control is 


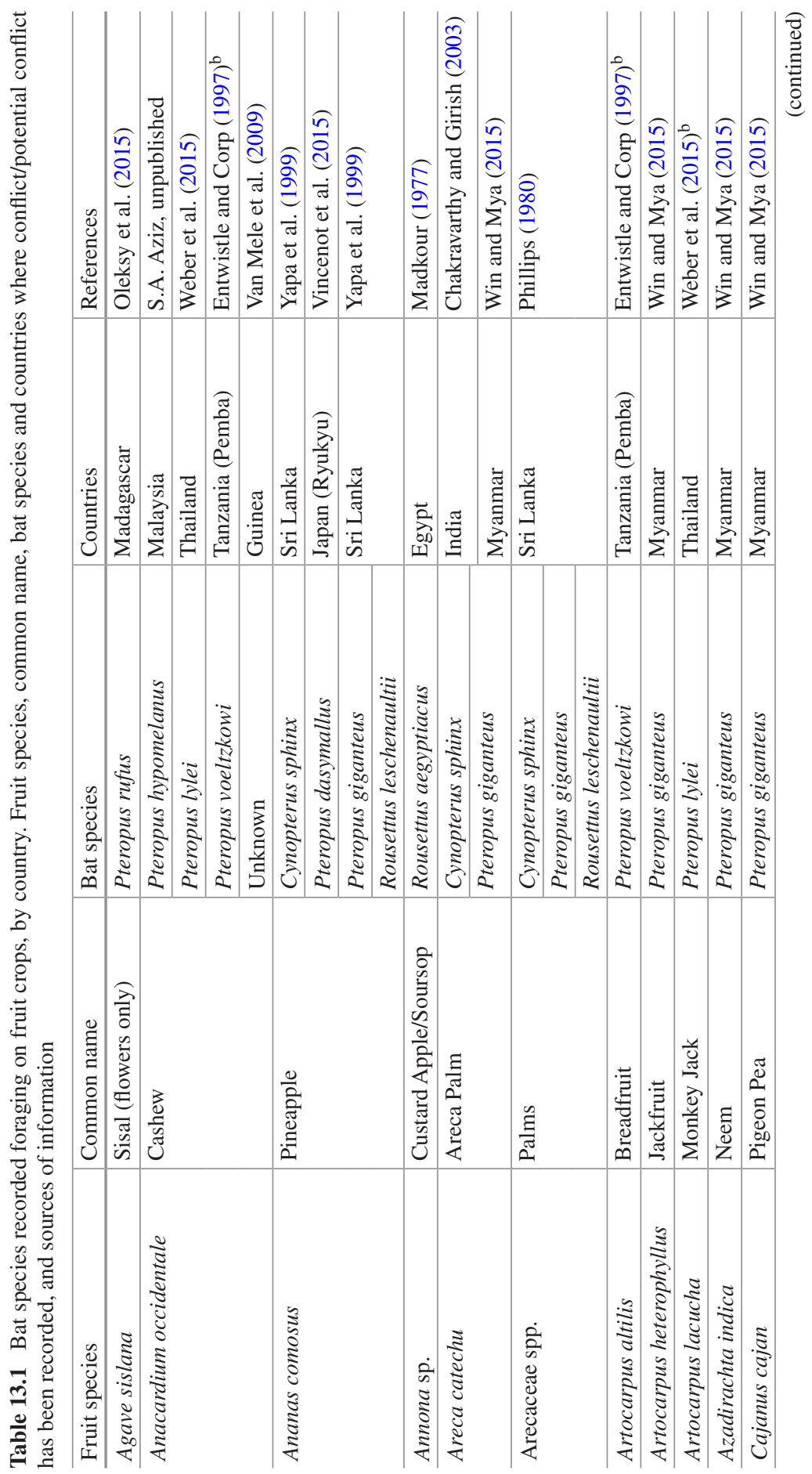




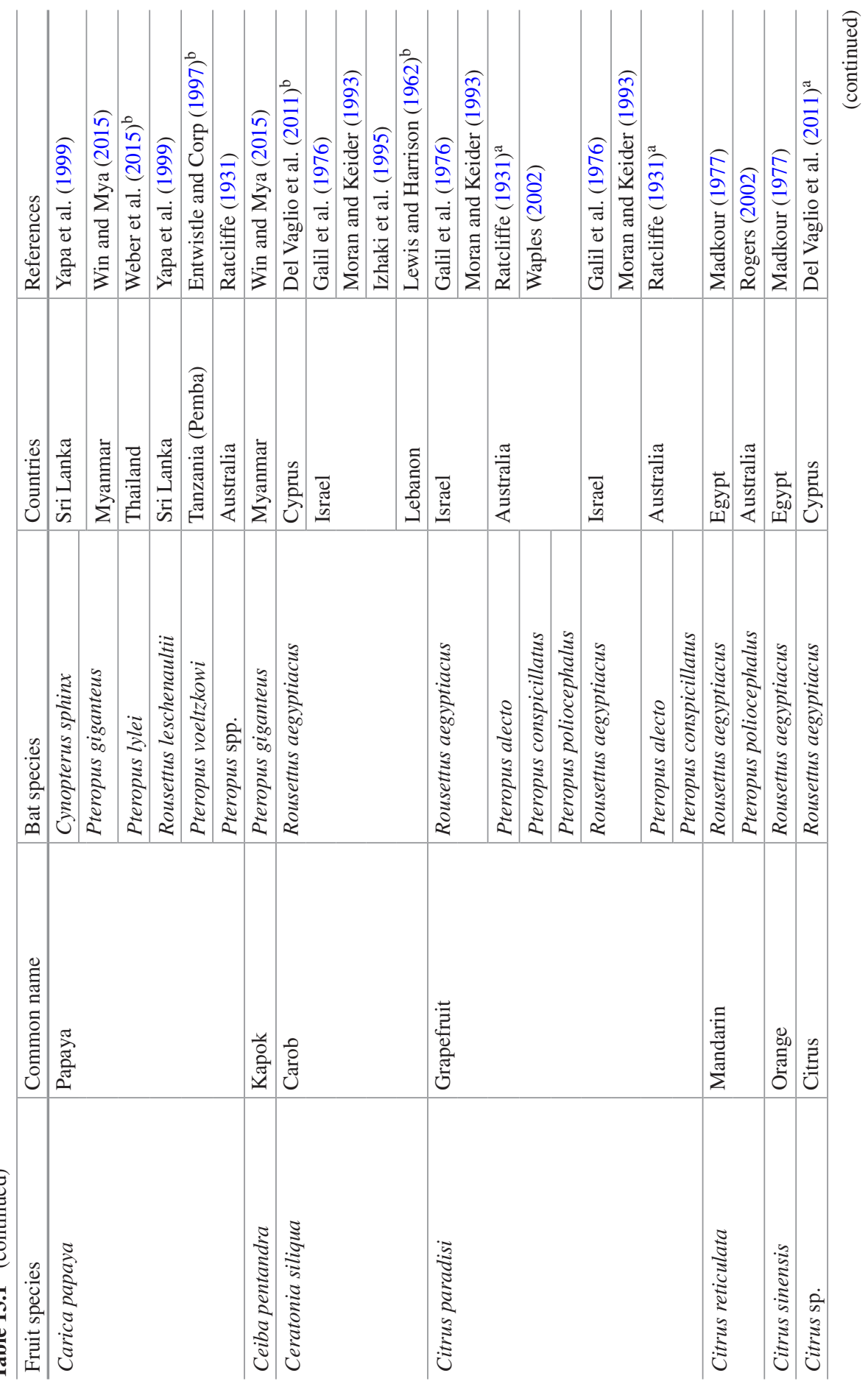




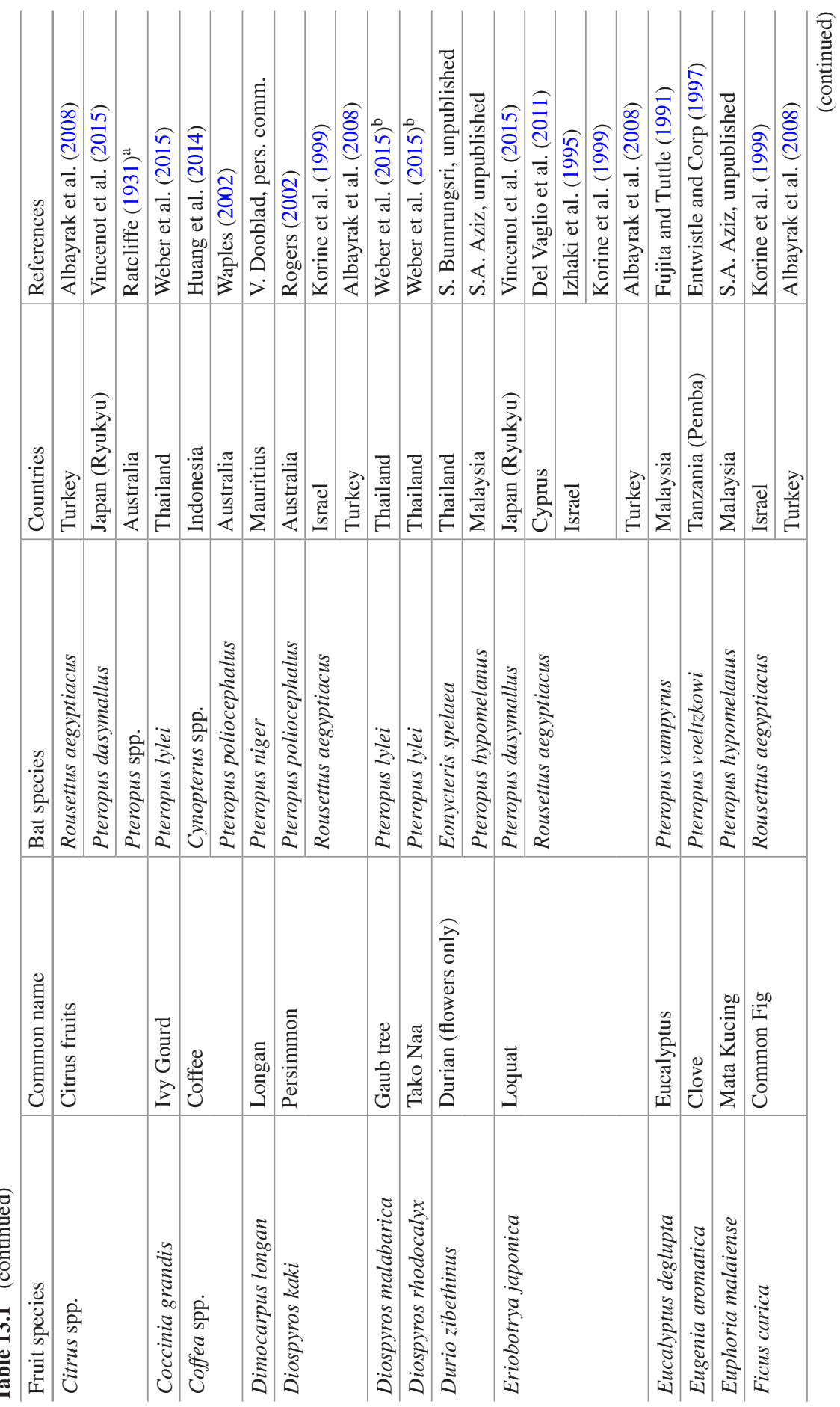


13 The Conflict Between Pteropodid Bats and Fruit Growers ...

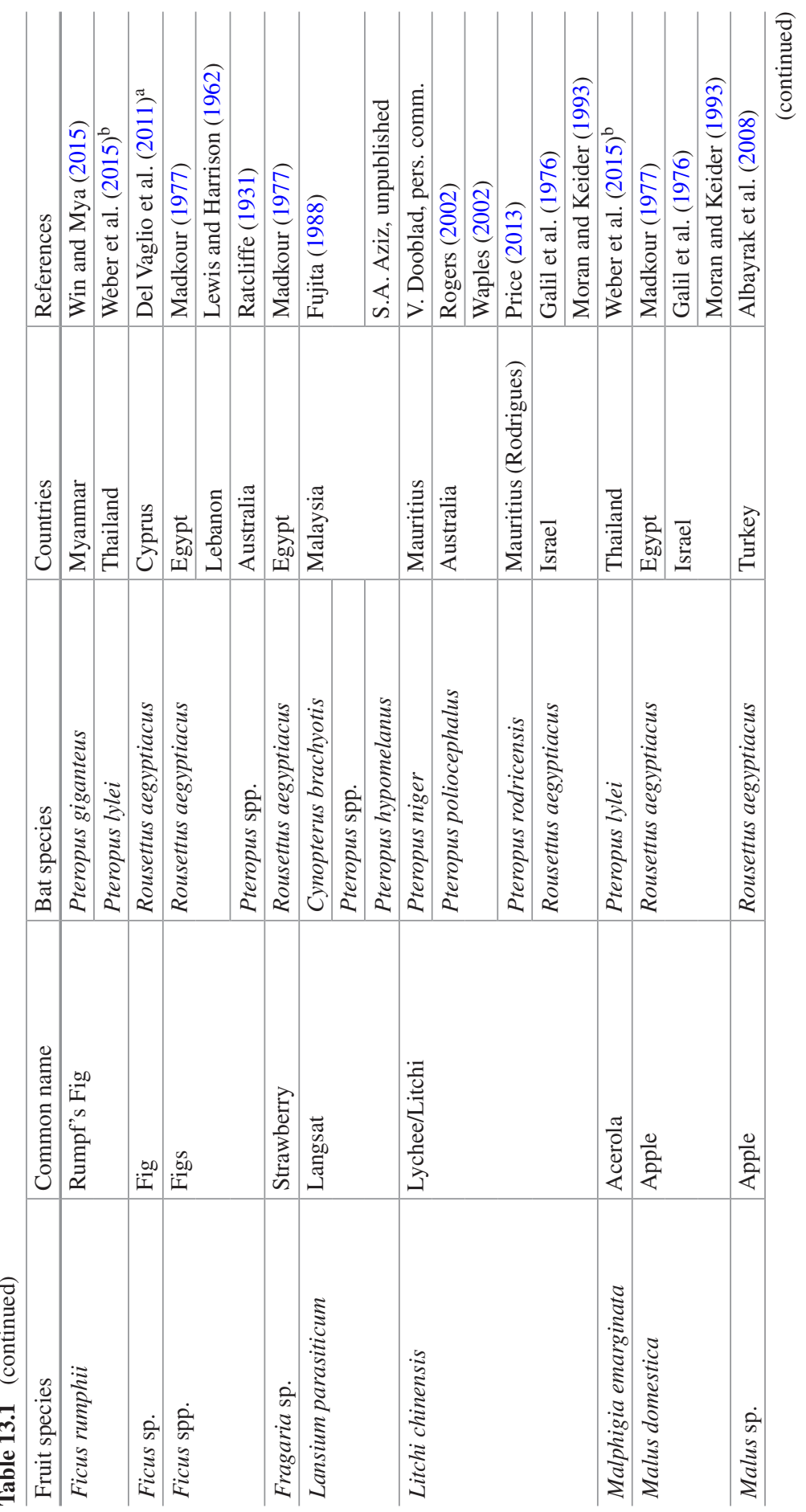




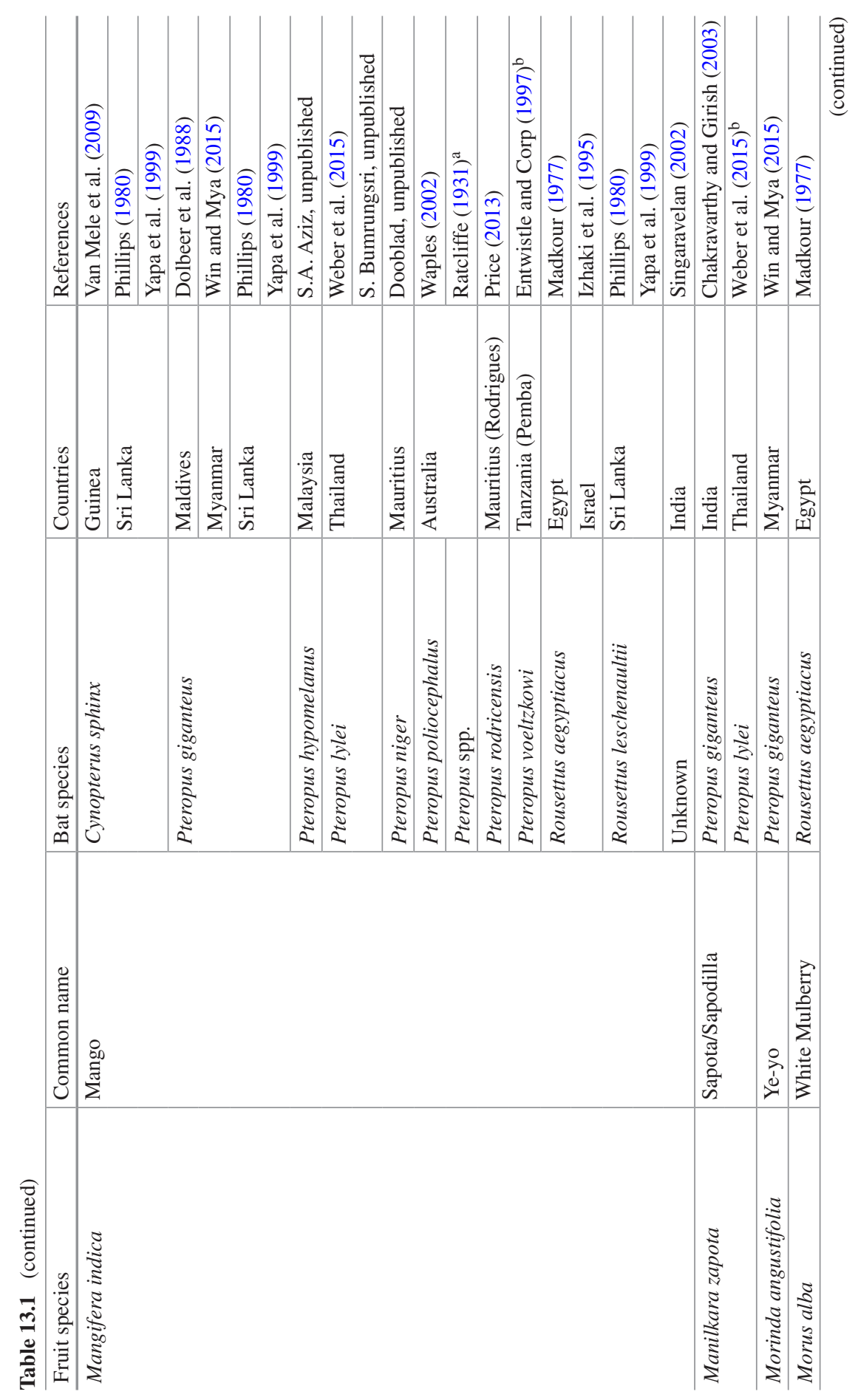




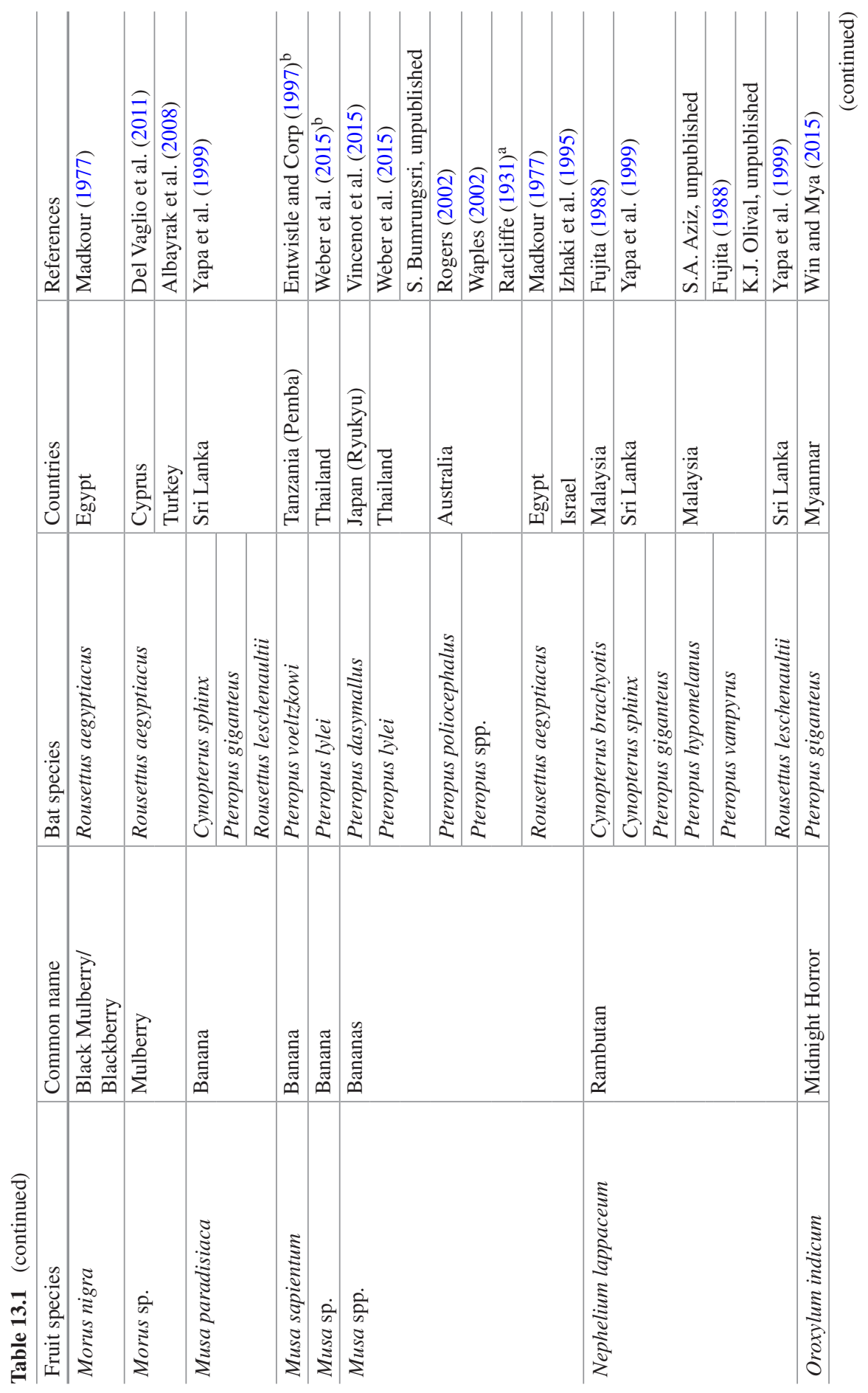




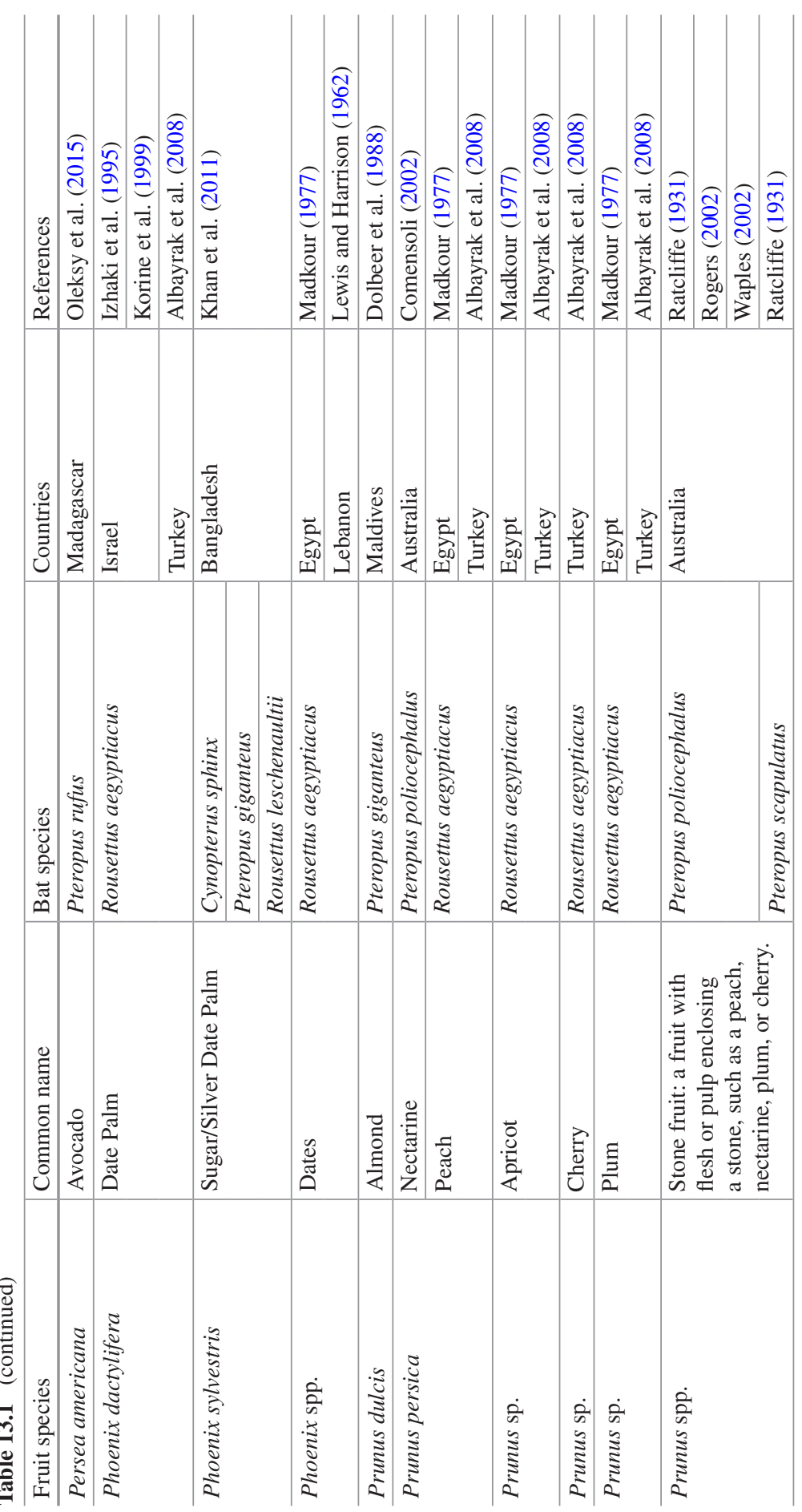


13 The Conflict Between Pteropodid Bats and Fruit Growers ...

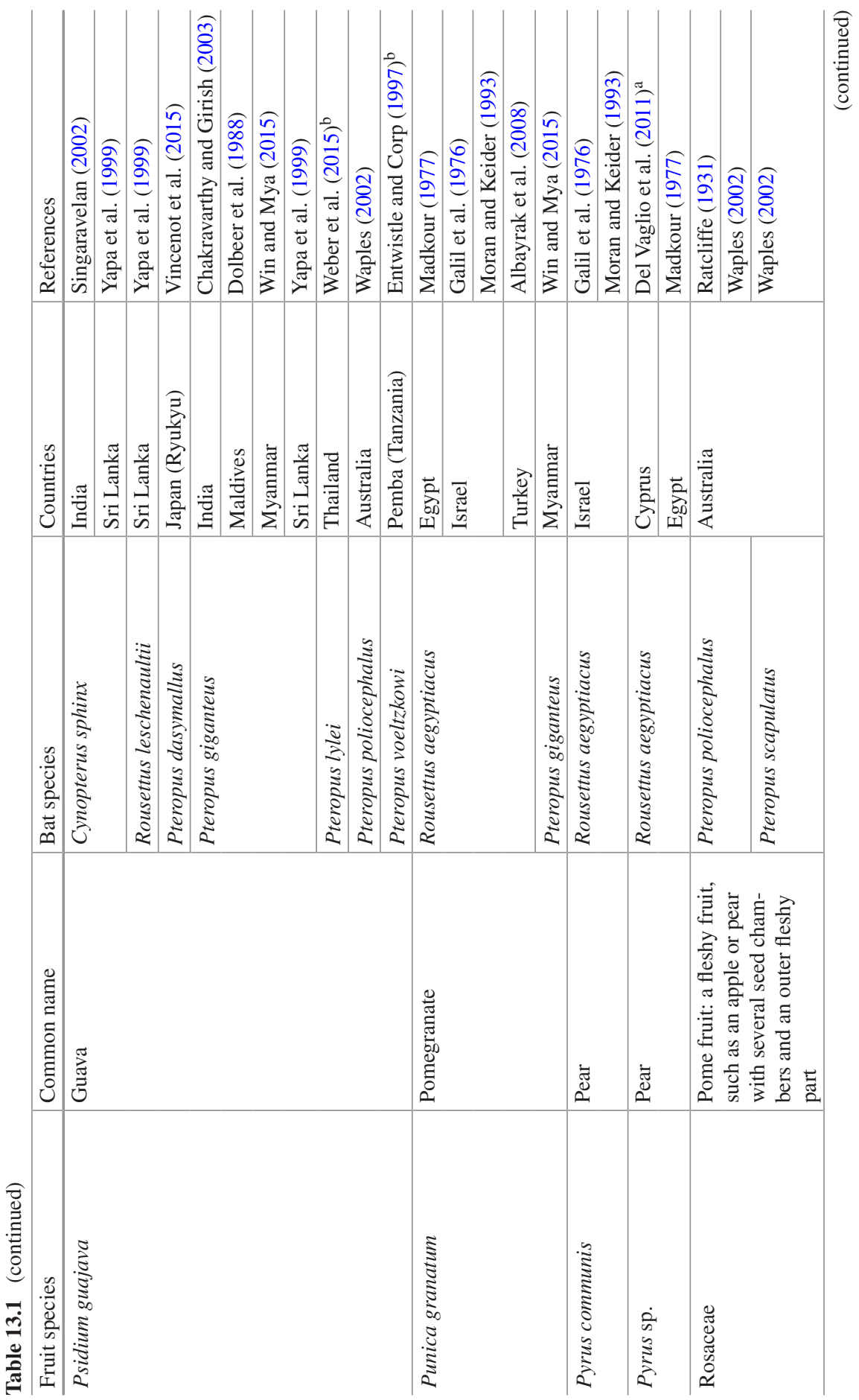




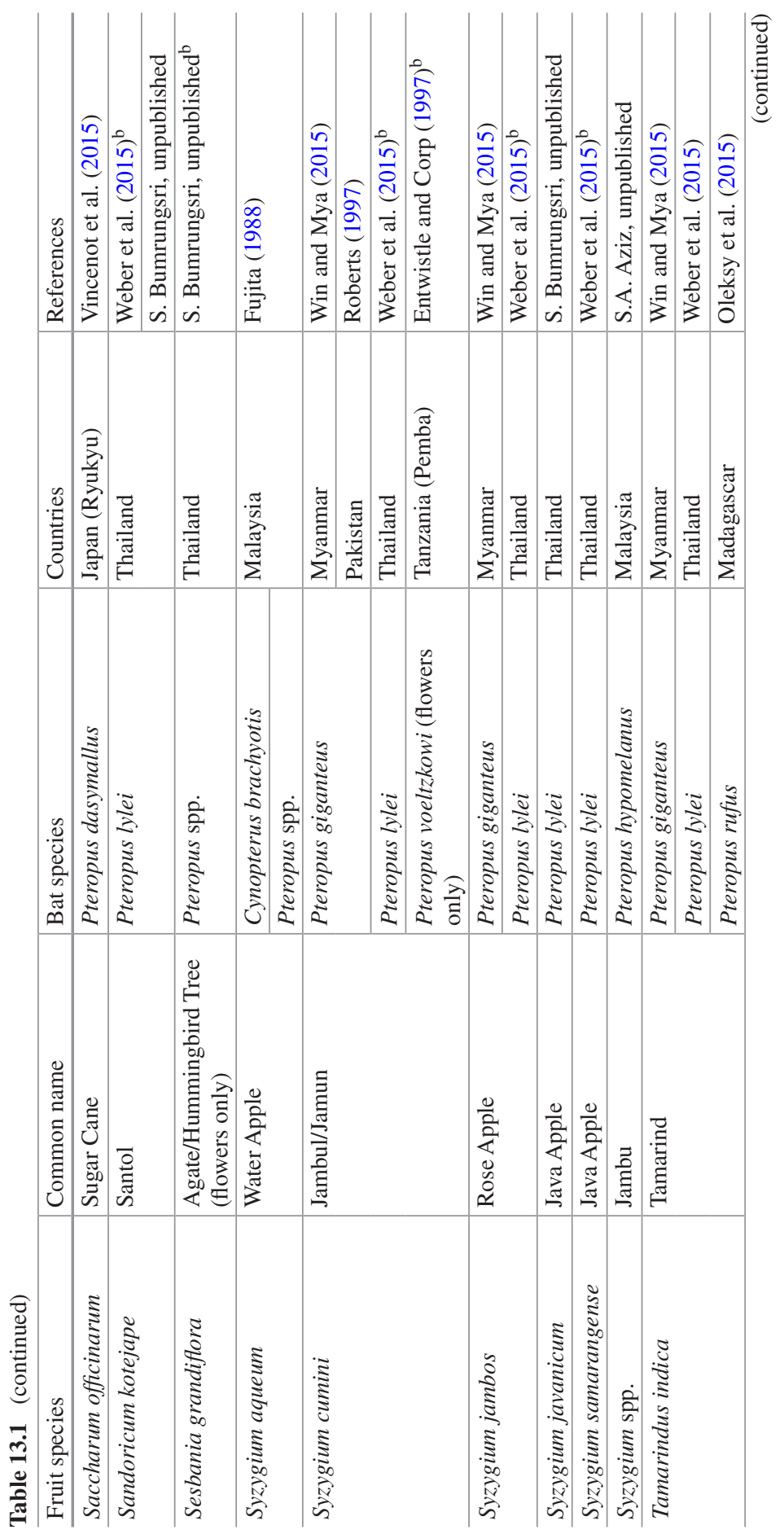




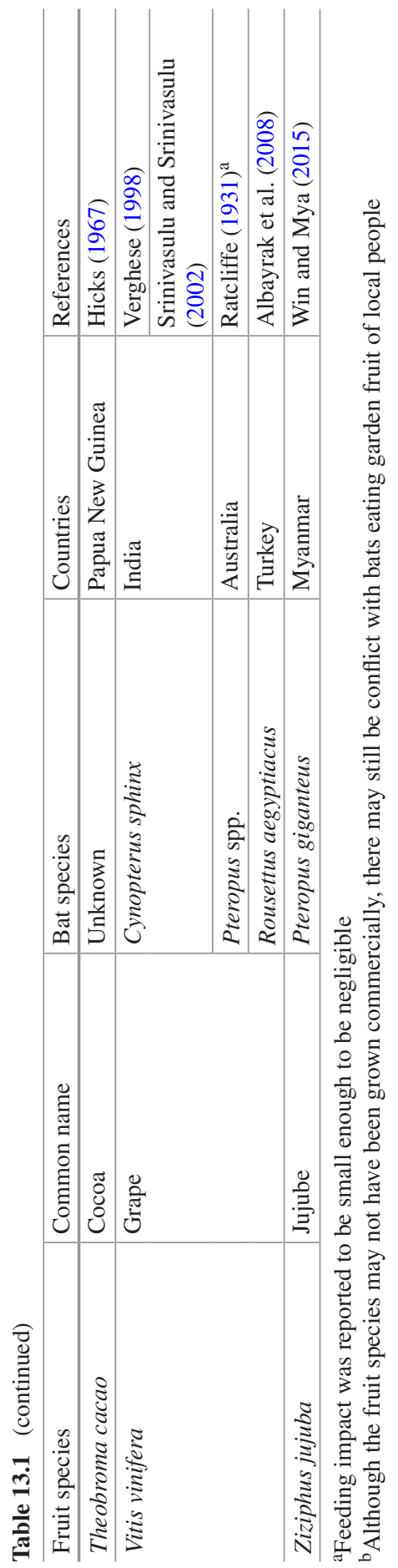


of great economic importance'. He reported that there were records of the species attacking cultivated fruit trees, and during the course of his study, they were recorded feeding on apple (Malus domestica), apricot (Prunus sp.), banana (Musa sp.), custard apple (Annona sp.), date (Phoenix sp.), mandarin (Citrus reticulata), mango (Mangifera indica), mulberry (black Morus nigra and white M. alba), orange (Citrus sinensis), peach (Prunus persica), pear (Pyrus sp.), plum (Prunus sp.), pomegranate (Punica granatum) and strawberry (Fragaria sp.). However, there was no mention of whether this was recorded from in situ observations or feeding trials in captivity.

Korine et al. (1999) showed that $R$. aegyptiacus in Israel ate mainly noncommercial fruits and also to a lesser extent leaves and pollen, challenging the assumption that this species is a major agricultural pest. Out of 14 identified plant species comprising its diet, only four are grown commercially in Israel: persimmon (Diospyros kaki), loquat (Eriobotrya japonica), fig (Ficus carica) and date (Phoenix dactylifera), with the largest component consisting of figs (Ficus spp.). The perception of $R$. aegyptiacus as a pest (Harrison 1964; Moran and Keidar 1993) led to conflict with farmers, resulting in extermination programs that reduced its population in the country (Korine et al. 1999; Hadjisterkotis 2006). As these control measures involved widespread fumigation of caves by the authorities, using the chlorinated hydrocarbon lindane, many populations of cave-dwelling insectivorous bats were also drastically reduced (Makin and Mendelssohn 1987). Other reports from Israel detail bats consuming commercial fruits such as apples, bananas, carobs (Ceratonia siliqua), dates, grapefruits (Citrus paradisi), lychees (litchi; Litchi sinensis), mandarins, pears and pomegranates (Galil et al. 1976; Moran and Keider 1993; Izhaki et al. 1995). However, the overall extent of actual damage to fruit crops is unknown and requires further detailed investigation.

In Lebanon, R. aegyptiacus was observed feeding on carobs, dates and figs. Its preference for dates and figs in particular, which are also cultivated for human consumption, caused it to be the only bat species considered to be of economic importance there. Farmers used shotguns to kill bats, and even though fruit such as dates could be protected by cloth bags or nets before ripening, this was seldom done. Some farmers were even known to starve populations of bats in caves by placing nets over the roost entrance (Lewis and Harrison 1962).

Qumsiyeh (1980) initially stated that the population of R. aegyptiacus in Jordan was increasing. However, more than a decade later, Qumsiyeh et al. (1992) concluded that the species was already under threat due to destruction of its roost sites, even though the issue of fruit crop damage had yet to be investigated in the country.

Albayrak et al. (2008) reported that in the Mediterranean region of Turkey, $R$. aegyptiacus fed on both wild and commercially grown fruits. Their study identified 15 different species, of which 13 were marketed: plum, loquat, apple (Malus sp.), fig (F. carica), pomegranate, grape (Vitis vinifera), persimmon, date, mulberry (Morus sp.), cherry (Prunus sp.), peach, apricot and citrus (Citrus sp.). Wild fruits were consumed only during the winter. They concluded that fruit bats could have a considerable impact on fruit crops, with farmers in Hatay Province 
claiming that bats consumed $10-15 \%$ of their loquat harvest. Fruit bats were thus considered to be serious pests and were subsequently killed regularly. According to Spitzenberger (1979), in the past, this involved fumigating roost caves or walling up their entrances. Harrison and Bates (1991) reported that farmers caged their commercial fruit trees in order to protect them from $R$. aegyptiacus. However, a more recent study in 2012 found that local people in Turkey did not consider bats to be as much of a problem as birds (E. Coraman, pers. comm.).

In Cyprus, only anecdotal reports were previously available for the diet of $R$. aegyptiacus. A preliminary assessment of its diet was carried out by Del Vaglio et al. (2011) from droppings, in order to determine the bats' real impact on crops. The diet consisted mostly of fruits, several species of which were the same as those reported by Korine et al. (1999) for Israel and Albayrak et al. (2008) for Turkey. The species is an opportunistic forager, with non-native plants forming an important component of its diet, yet Del Vaglio et al. (2011) concluded that its damage to economically important plants in Cyprus is negligible. Their study found that the bat fed mainly on wild fruits and escaped ornamental plants and that only five out of the 11 plant species it consumed-citrus, fig, loquat, mulberry and plum-were grown as commercial fruit crops in Cyprus.

\subsubsection{Africa and the Indian Ocean}

In Guinea, mango and cashew (Anacardium occidentale) farmers listed fruit bats among the mammals (together with monkeys, squirrels and other rodents) that cause damage to their harvest. The bats target ripening mangoes and cause significant damage, identified by a visible seed protruding from the eaten lower part of the fruit. However, only $4 \%$ of farmers identified fruit bats as pests, compared to $92 \%$ who identified fruit flies as the most significant pest. Overall, according to the farmers, five species of insects, followed by squirrels, caused greater damage than bats. The majority of farmers did not carry out any pest management (Van Mele et al. 2009).

Entwistle and Corp (1997) examined the diet of Pteropus voeltzkowi), which is endemic to the island of Pemba, off the coast of Tanzania. They found that it consisted of a high proportion of cultivated fruit grown on 'shamba' plots, in particular mangoes which formed a key component of the diet during the duration of the study. Breadfruit (Artocarpus altilis) was also consumed. In addition, interview surveys with villagers and students yielded additional cultivated fruit species among the food plants of this bat species (Table 13.1).

In the Indian Ocean, Dolbeer et al. (1988) described the Indian flying fox (Pteropus giganteus) as a major cause of damage to almonds (Prunus dulcis), guavas (Psidium guajava) and mangoes in the Maldives, although losses were not quantified. In Mauritius, the Agricultural Research and Extension Unit of the Food and Agricultural Research Council estimated an overall average of $10 \%$ of orchard lychee fruit was damaged by the Mauritian flying fox (Pteropus 
niger). Ten trees were studied in each of three orchards and damage to individual fruit averaged 2, 7, and $17 \%$. In contrast, a smaller study of four longan trees (Dimocarpus longan) recorded damage to all fruit panicles. Mangoes were also damaged at a rate of 10-30 \% (V. Dooblad, pers. comm.). In contrast, a recent study by Ramlugun (2013) in a lychee orchard found that high winds and introduced birds, but not bats, resulted in fruit losses of 30 and $9.5 \%$, respectively. On Rodrigues (an autonomous island of the Republic of Mauritius), losses to backyard mango and lychee production were estimated at about $36 \%$, much of which was perceived to be to the Rodrigues flying fox (Pteropus rodricensis) (Price 2013).

Oleksy et al. (2015) carried out GPS tracking of the Madagascan flying fox (Pteropus rufus) to determine its foraging movements and habitat selection in south-eastern Madagascar. The study revealed that this species has a strong preference for feeding on the nectar and pollen of sisal (Agave sislana) in overgrown plantations. These bats also feed on the fruits of avocado (Persea americana), lychee, mango and tamarind (Tamarindus indica). However, it was not mentioned whether this causes any conflict issues.

\subsubsection{Indian Subcontinent}

Bats are causing increasing economic loss in the Indian grape industry due to a decline in wild fruits and flowers, coupled with the increase of grape-growing areas. Verghese (1998) first drew attention to the damage caused by the greater short-nosed fruit bat (Cynopterus sphinx) to grapes in Bangalore where the vines are trained to grow on overhead trellises. They entered the vineyard through canopy gaps in the bower, not from the sides, and consumed only the juice of the fruit, while the pulp, seed and skin were discarded. Signs of bat damage included these remnants littered at the base of the grape vine, as well as grape bunches with bare stalks. The damage was greater in parts of the vineyard adjacent to open spaces, suggesting that growing non-commercial trees around the entire vineyard might deter bat foraging. Damage was lower in vines situated closer to an adjacent mango orchard.

Similarly in Andhra Pradesh State, Srinivasulu and Srinivasulu (2002) showed that the magnitude of damage caused by $C$. sphinx to grapes varied with the distance of the vines from the periphery of the vineyard. Damage was extensive $(90 \%)$ at the periphery, but none was recorded in the centre, where the higher density of the vines made approach flights difficult. In contrast, in Tamil Nadu State, $C$. sphinx was not known to damage grape crops; rather, eight bird species were the primary crop pests. There were also no records of this bat species damaging sapota (Manilkara zapota) in that state; however, considerable damage was reported to mango and guava crops (Singaravelan 2002).

In the State of Karnataka, Chakravarthy and Girish (2003) recorded losses of $18 \%$ of areca nuts (Areca catechu) caused by a population of 3500-4000 P. 
giganteus and 2-28 C. sphinx. Bats also damaged 13-22\% of sapota fruits, although higher levels of damage were inflicted by birds. Up to $28 \%$ of guava fruits were also damaged by bats. $C$. sphinx has also been recorded as damaging mango and guava in Tamil Nadu State but did not damage sapota (Singaravelan 2002).

In Bangladesh, $P$. giganteus feeds on date palm sap (Phoenix sylvestris), widely harvested in the country as a beverage in the winter months (December-March) (Luby et al. 2006). Infrared camera traps have recorded P. giganteus and other pteropodid species (Cynopterus spp. and Rousettus leschenaultii) drinking from clay pots used to collect the sap at night (Khan et al. 2011), although the magnitude of the loss has not been investigated. This bat-plant sap interaction is a route for the transmission of zoonotic disease (see 13.3).

In Pakistan, $P$. giganteus is also labelled as vermin due to a perception that it raids fruit crops in orchards (Mahmood-Ul-Hassan et al. 2010). Apart from areca nuts, sapota and guava, it is also blamed for heavy economic losses of crops of mango and jamun (Syzygium cumini) (Roberts 1997; Chakravarthy and Girish 2003). However, a dietary study conducted by Mahmood-Ul-Hassan et al. (2010) in Lahore found that $P$. giganteus feeds primarily on wild figs rather than commercial crops. The study concluded that the perception of $P$. giganteus as a pest is a misconception, and its economic value as a pollinator is far greater for the fruit industry.

In Sri Lanka, according to Yapa et al. (1999), fruit farmers claimed that pteropodid bats (C. sphinx, R. leschenaultii and P. giganteus) damage fruit trees in plantations and home gardens. Fruits that were specifically identified as suffering heavy damage by $C$. sphinx were mango and rambutan (Nephelium lappaceum), with mango thought to be particularly vulnerable in monoculture plantations. Bananas (Musa paradisiaca), papayas (paw-paws; Carica papaya) and even pineapples (Ananas comosus) were apparently also targeted. Their study concluded that $C$. sphinx was 'capable of causing heavy damage' and could thus potentially be a 'major fruit pest'. Earlier, casual records collected by Phillips (1980) also reported guava, mango, soursop and several palm species being consumed by pteropodids in Sri Lanka.

\subsubsection{Southeast Asia}

Although there are 95 species of pteropodids, including 31 flying foxes (IUCN 2014) in Southeast Asia, there is little published information on fruit crop damage caused by bats. Perception of damage is however widespread and has implications for conservation. For example, it may explain the Malaysian government's reluctance to provide full protection for the nation's flying foxes (large flying fox Pteropus vampyrus and island flying fox P. hypomelanus) by halting licensing which has led to unsustainable hunting (Epstein et al. 2009). So far, little attempt has been made to investigate the issue of conflict or quantify the economic loss. 
Fujita (1988) reported that pteropodid bats, specifically flying foxes and the lesser dog-faced fruit bat (Cynopterus brachyotis), are considered pests by orchard owners interviewed in Malaysia and Indonesia and are therefore shot when they visit these orchards. Fruit growers considered bats to be particularly problematic for rambutan, langsat (Lansium parasiticum) and water apple (Syzygium aqueum), which are all important market fruits. The owner of one of the largest langsat orchards in Peninsular Malaysia revealed that if measures were not taken to protect his fruit crop several days prior to harvest, $20 \%$ of the crop would be lost to bats. However, he also considered that simple protective measures could be undertaken such as shining bright lamps, lighting fires under the trees, or shooting to scare the bats away, in which case the damage would be negligible. This same orchard owner also appeared to display an understanding of the importance of pteropodids as seed dispersers-he considered that almost all of the langsat trees in his village resulted from seeds dropped by bats. His langsat fruit was typically harvested for sale in the local market.

Fujita and Tuttle (1991) conducted some preliminary investigations into bat pest control in Malaysia and Indonesia, interviewing six plantation/orchard owners and six professional hunters. Owners employed bounty hunters to eradicate bats during flowering and fruiting seasons who could earn up to USD 3 per bat, shooting as many as 100 in one night from a single plantation. A group of three to five hunters regularly patrolled an orchard, using bright lights to locate the bats. According to one hunter, up to seven bats could be hit with a single shot (Fujita 1988). These bats were killed in disproportionately large numbers despite plantation/orchard owners reporting that more significant damage was caused by other animals such as giant squirrels (Ratufa spp.), pig-tailed macaques (Macaca nemestrina), binturong (Arctictis binturong), Timor deer (Cervus timorensis) and bearded pigs (Sus barbatus). A professional hunter employed by a pulp and paper plantation in Sabah (Malaysian Borneo) reported that in 1983 alone he purchased 2000 rounds of ammunition for sport shooting of flying foxes that were attracted to the eucalyptus flowers. He also reported that bats were killed in the thousands annually during 1983 and 1984, but that their numbers had been drastically reduced by 1985 (Fujita and Tuttle 1991). Using population models based on roost census data and numbers of hunting permits issued in Peninsular Malaysia, Epstein et al. (2009) found that rates of hunting were unsustainable and would lead to local extinction of $P$. vampyrus.

Gumal et al. (1998) acknowledged that in Sarawak (Malaysian Borneo), an increase in commercial fruit crops, coupled with the loss of habitats such as beach forests, mangroves and peat swamps, has resulted in flying foxes foraging in orchards and farms. This encroachment has led to them being labelled as pests, and it is reasonable to assume that a similar situation occurs in Sabah and Peninsular Malaysia.

On Tioman Island (Peninsular Malaysia), P. hypomelanus was reported by local people to feed on a wide range of cultivated fruit trees in their villages, where the bats also roost. This happens despite the fact that wild food resources are still widely available in nearby largely intact forest and has resulted in conflict with villagers despite the fruit being cultivated for personal consumption rather than 
a source of livelihood. Seeds of mango, cashew and rambutan have been found beneath day roosts, and people also frequently reported that the bats feed on langsat, mata kucing (Euphoria malaiense) and various types of Syzygium fruits. Durian (D. zibethinus) pollen has been found in flying fox faeces, and cameratrapping in durian trees has confirmed that $P$. hypomelanus feeds on durian flowers. Preliminary observations of feeding behaviour suggest that only the nectar is sought, leaving the flowers intact on the branch, and as such, these bats probably perform an important pollination service. Yet some villagers believe that the bats damage or remove the flowers, thereby affecting fruit set (S.A. Aziz, unpublished).

Farmers in Peninsular Malaysia use large, treble fishing hooks and monofilament line set in fruit orchard trees to capture flying foxes. This inhumane method is often lethal, and its efficacy in protecting crops has not been tested. One male $P$. vampyrus used in a satellite telemetry study was captured in a rambutan orchard in Johor, Malaysia, using this method and released after sustaining minor injuries (Epstein et al. 2009; K.J. Olival, unpublished). Gumal et al. (1998) concluded that there is a need to investigate non-lethal methods for protecting orchards and fruit gardens against bats.

In 2005, a newspaper article highlighted the overall decline of Pteropus in Malaysia, attributing it to logging and hunting (Teoh 2005). Interestingly, it cautioned that this would negatively affect cash crops such as durian (D. zibethinus), petai (Parkia speciosa), rambutan and langsat, highlighting the flying fox's role as a pollinator for these trees. However, some confusion may have arisen between flying foxes (Pteropus spp., Acerodon spp.) and smaller fruit bats such as E. spelaea, since Fujita (1988) and Fujita and Tuttle (1991) use the term to refer to all bats of the family Pteropodidae.

In southeast Thailand, fruit farmers stated that Lyle's flying fox (Pteropus lylei) damages less than $10 \%$ of harvestable mangoes, and far fewer bananas, water apples (Syzygium javanicum) and santol (Sandoricum koetjape). Damage is reduced when fruit trees are mixed compared to monoculture systems. Farmers with mango monocultures treated flying foxes as pests, but most farmers with mixed fruit orchards did not regard them as such (S. Bumrungsri, unpublished). According to these farmers, these flying foxes feed mainly on several fig species, especially $F$. religiosa which is regarded as a sacred tree in Buddhist Thailand. These figs are common in the landscape, particularly in temples. Flying foxes also feed on flowers of the agate or hummingbird tree (Sesbania grandiflora), commonly found across South and Southeast Asia and in villages in Thailand, where the flowers and young pods are consumed by people. Farmers also mentioned that flying foxes forage in groups of 10-15 individuals and keep returning to the same feeding area on consecutive nights (S. Bumrungsri, unpublished).

More recently, Weber et al. (2015) conducted GPS tracking of P. lylei in central Thailand. Tracked bats were found to forage mostly in farmland, plantations and gardens. All 34 recorded food plant species were noted to also be useful to local people, though not necessarily as fruits for sale or consumption. Thirty-one species were identified as fruit resources, and an unspecified $42 \%$ of these were cash crops (therefore, the only species listed in Table 13.1 are ones that the authors know are cultivated by people in Southeast Asia for either fruits or flowers). Only mango, 
cashew, banana and tamarind were mentioned specifically as having high economic value or as being cultivated crops. Mangoes were also the most frequently eaten fruit, followed by bananas and tamarind. Such competition for resources between bats and humans was acknowledged as a potential source of conflict. Local farmers confirmed that flying foxes are hunted as an orchard pest in this area.

In Indonesia, Huang et al. (2014) have studied Cynopterus feeding in coffee (Coffea spp.) plantations in Sumatra. Most growers (93\% of 16 interviewed) reported that bats visit their plantations. Coffee berries are taken to feeding perches and the beans discarded after the pericarp is eaten. This study is now investigating the potential of marketing bat-discarded coffee beans as a premium wildlife product.

A recent dietary study on $P$. giganteus in the Mandalay region of central Myanmar (Win and Mya 2015) also interviewed local villagers to determine the extent of conflict between flying foxes and fruit tree owners. The bats were found to feed on 24 fruit species, 13 of which were also eaten by people. Of these, only three-guava, mango and tamarind-were of commercial importance. Morinda angustifolia and Azadirachta excelsa are used for medicinal purposes, while Ceiba pentandra is still used for stuffing pillows (a practice that is dying out in other Southeast Asian countries). Despite this, local people view the bats positively, and no conflict was reported. The authors of the study concede that a superabundance of mangoes is one reason why people are still willing to tolerate a certain amount of fruit loss.

\subsubsection{Australia and Papua New Guinea}

Australia has the oldest and most comprehensive records documenting the issue of flying foxes and fruit crop damage. Ratcliffe (1931) provided detailed reports on 'depredations' by flying foxes on both commercial orchards and garden trees in New South Wales (NSW) and Queensland. Although flying foxes were known to feed on bananas, citrus fruits, mangoes and grapes, losses were not significant enough for the bats to be considered 'economic pests'. Slight losses were reported for papayas, some losses for pome fruit (fruits of the family Rosaceae having several seed chambers and an outer fleshy part, such as an apple or pear) and stone fruit (fruits of the genus Prunus with flesh or pulp enclosing a stone, such as a peach, nectarine, plum, or cherry), and heavy losses for figs (Ficus spp.). For some fruits such as bananas, mangoes and papayas, the regular practice of picking them before they ripen was often sufficient to avoid heavy losses to flying foxes.

Despite these known losses, the extent of flying fox damage to commercial fruit has seldom been quantified in Australia, even in more recent reports. Eby (1995) refers to 'substantial financial loss to growers' and lists a relatively large number of commercial exotic fruits on which Pteropus spp. feed, although damage was of particular concern to growers of stone fruits and banana. Stacey (1990) refers to heavy stone fruit losses during the prolonged drought conditions of 1986, with bats eating immature green fruit. Waples (2002) reported that most requests for licences to shoot flying foxes in NSW came from growers of stone fruits and lychee, but that damage was also reported to guava, mango, banana, pome fruits 
and coffee. Signs of damage include broken branches, clawed fruit and fruit remnants under trees (Comensoli 2002). Ullio (2002) reported that from 1995 to 2000, fruit growers in NSW suffered an annual gross market value loss of AUD 10.4 million due to consumption by flying foxes. When taking into account the resulting loss to affiliated industries such as packaging, employment, transport and marketing, the overall financial loss was estimated to be around AUD 26 million annually. Prior to 1998, on the north coast of NSW, only stone fruit, lychee and persimmon were consistently eaten by flying foxes in significant quantities (Rogers 2002). Losses increased dramatically from 1998, particularly in orchards without netting. The stone fruit industry suffered a loss of AUD 4-6 million (not including preharvest costs, which usually exceed AUD 20,000). Sixty per cent of orchards without netting suffered losses of 50-100\%, around AUD 45,000 per grower. The mandarin industry reports losing at least $40 \%$ of its annual crop, while in 2001, an individual lychee grower reported a loss of more than AUD 500,000 in the unnetted section of her orchard (Rogers 2002). Comensoli (2002) measured the damage caused by flying foxes to his nectarine ( $P$. persica) orchard, estimating that $20 \%$ of ripe fruit was damaged over a period of 19 days, reducing the annual profit from his entire crop by $16 \%$. In Queensland, orchardists also suffered particularly high crop damage in the summer of 1998. The estimated total loss for that season was approximately AUD 10 million (Teagle 2002), with some growers having lost up to $90 \%$ of their crop (Dewhurst 1998). It should be noted, however, that the above estimates of orchard losses have not been verified and originate primarily from growers.

Due to this perceived high economic loss, the Australian fruit industry considers species of Pteropus to be its main vertebrate crop pests (Ullio 2002). Yet it has been acknowledged, even among fruit growers, that increasing feeding by flying fox on commercial crops is due to the loss of natural food resources as the rainforests, heathland and Melaleuca swamps of Australia's eastern seaboard have been increasingly cleared for urban development (e.g. Bicknell 2002; Biel 2002; Gough 2002; Rogers 2002). As a result, Biel (2002) and Rogers (2002) proposed that fruit growers should be financially compensated for economic loss and that the wider community should also bear the cost of mitigation and biodiversity conservation.

Details of bat-grower conflict in Papua New Guinea are scant, but a report by Hicks (1967) stated that bats and birds together caused the loss of $8.7 \%$ of cocoa (Theobroma cacao) pods from an orchard from 1962 to 1965.

\subsubsection{The Pacific}

Luskin (2010) studied the foraging behaviour of the Pacific flying fox (Pteropus tonganus) in a landscape mosaic in Fiji. He found that mean foraging density was four times higher in farmland compared to native dry forest, with high foraging competition taking place almost completely in farmland alone. Severe deforestation has resulted in a large bat population that has shifted away from feeding on flowers in forests to feeding more on fruits in farms. However, no observations 
were made on which type of fruits suffered predation. Farmland resources, with their higher fecundity, now appear to be the staple of $P$. tonganus' diet. Daily, crepuscular mass migration from forests to farmlands has reduced feeding density in forests, thus reducing the aggressive feeding interactions needed to catalyse effective seed dispersal necessary for forest regeneration (McConkey and Drake 2006). The loss of this ecological role could be disastrous for Pacific tropical dry forest, which is a critically endangered habitat (Myers et al. 2000). Also, while the abundance of farmlands has buffered the flying fox population from the effects of extensive deforestation, further research is needed to determine what damage or effects this may have on fruit crops, as well as flying fox nutrition.

In Japan, previous studies on the Ryukyu flying fox (Pteropus dasymallus) focused on diet and did not report any conflict with humans (e.g. Funakoshi et al. 1993; Nakamoto et al. 2007, 2009; Lee et al. 2009). In the Ryukyu Archipelago, Nakamoto et al. (2007) reported that Orii's flying fox (P. dasymallus inopina$t u s$ ) on Iriomote-jima Island is a generalist forager, with almost $50 \%$ of its diet consisting of cultivated or naturalised plants. The majority $(67.9 \%)$ of its diet throughout the year is composed of fruits. Although its main food resource is Ficus microcarpa, the subspecies appeared to adopt a varied diet through intense use of abundant planted trees, as a response to unstable food conditions in an urban environment. Some of these plants are from gardens, parklands and walkways, but others are agricultural plants from plantations. On Iriomotejima Island, Lee et al. (2009) found that the Yaeyama subspecies (P.d. yayeyamae) had a comparably less diverse diet and was more abundant in forest compared to cultivated areas, with figs again dominating its diet. Yet bats were still observed in larger groups frequenting villages containing fruit trees. Neither study mentioned predation of economically important fruit as being an issue of concern, and conflict with humans had not been previously identified by anyone as a threat for this particular species.

However, a more recent study by Vincenot et al. (2015) has revealed for the first time that farmers do indeed kill P.d. yayeyamae, illegally, because it feeds on crops. Face-to-face interviews and direct observations have shown that flying foxes are frequently killed either through netting, poison or physical beatings, to stop them from feeding in plantations of banana, citrus, guava, loquat, pineapple and sugar cane (Saccharum officinarum). This persecution has clearly contributed to continuing declines that were noticeable to interview respondents, and which contradicts the IUCN's decision in 2008 to downgrade the Red List status of $P$. dasymallus from endangered (EN) to near threatened (NT).

\subsection{Food-Borne Zoonotic Disease Risk from Pteropodid Bats}

An additional concern to crop damage caused by pteropodid bats is the potential for zoonotic disease transmission via fruit contaminated with bat excreta (i.e. saliva, urine, faeces). Old World fruit bats are natural reservoirs to a number of 
such diseases, including several emerging viruses that have limited or no pathogenicity in their bat hosts but high fatality rates in people. These include Ebola viruses (Leroy et al. 2005), Marburg virus (Towner et al. 2009), Nipah virus (Rahman et al. 2013), Hendra virus (Halpin et al. 2000), and lyssaviruses in Australia (Mackenzie et al. 2003) and Thailand (Lumlertdacha et al. 2005). While the transmission pathway for each virus is not always known, there is compelling evidence, in a small number of cases, that points to a food-borne route, most notably multiple spillover events of Nipah virus from Pteropus giganteus to people in Bangladesh (see below). Filoviruses (Ebola and Marburg) are also of great consequence to human health, as evident from the large west Africa outbreak of Zaire Ebola virus that began in early 2014. Much remains unknown about the natural hosts and ecology of filoviruses in bats (Olival and Hayman 2014), but Ebola virus may be transmitted from bats to humans through faeces (Swanepoel et al. 1996), but most likely through direct contact with blood (i.e. preparing hunted bats) (Leroy et al. 2009) or via contact with dead-end host carcasses (e.g. gorillas) (Leroy et al. 2004). Recent experimental studies have shown that Marburg virus can be excreted in bat saliva, answering important questions about its potential zoonotic spread via the oral route (Amman et al. 2014a). It has been postulated that bats and gorillas may share Ebola virus through contact at shared fruit resources, but this has not been verified and additional research is needed to better understand the ecological connections between bats and other mammal hosts in the transmission of these diseases (Groseth et al. 2007; Olival and Hayman 2014).

Henipaviruses (Hendra and Nipah viruses) are recently emerged paramyxoviruses that originate primarily from Pteropus spp. as their natural reservoir. Transmission of Hendra virus in Australia and Nipah virus in Malaysia from bats to intermediate or amplifying domestic animal hosts (horses and pigs, respectively) likely occurred though consumption of partially chewed fruit contaminated with bat saliva or ingestion of bat urine under bat foraging sites (Field et al. 2001; Chua et al. 2002). Henipaviruses have been shown experimentally to remain viable on the surface of mango and in other tropical fruit juices (lychee and papaya) from $2 \mathrm{~h}$ to 2 days depending on temperature and pH (Fogarty et al. 2008). Similarly, Chua et al. (2002) successfully isolated Nipah virus from a fruit in the wild that was partially eaten by $P$. hypomelanus. Thus, the risk of oral transmission of henipaviruses to humans via consumption of partially chewed fruit exists, although it is likely to be low. However, direct transmission of Nipah virus from bats to people occurs in Bangladesh nearly every year through the consumption of date palm sap, presumably contaminated with urine, saliva or faeces from infected $P$. giganteus (Luby et al. 2006; Rahman et al. 2012). Preventive measures are being used to block bats' access to date palm sap collection pots and reduce the risk of Nipah virus transmission (Nahar et al. 2010). Other mitigation measures that reduce the overall damage of crops by pteropodid bats will further mitigate any risk, however small, of zoonotic disease transmission via this route. Culling bat populations as a form of disease control is rarely effective and often has the opposite effect of increasing transmission and risk. This was recently demonstrated 
during an attempt to eradicate a population of $R$. aegyptiacus as a form of Marburg virus control, where prevalence of the virus significantly increased after the cull (Amman et al. 2014b). Additional approaches to reducing bat-human contact at potential disease interfaces should be developed, and disease mitigation should be carried out in a way that reduces risk without impacting bat populations.

\subsection{Legislative Approach to Reducing Pteropodid Damage to Crops}

\subsubsection{Australia}

Australia has 13 species of pteropodids, seven of which are flying foxes. Some are listed under the federal government's Environmental Protection and Biodiversity Conservation (EPBC) Act 1999 and several state wildlife protection laws.

Flying foxes became protected species in the State of New South Wales (NSW) in 1986 under the National Parks and Wildlife Act 1974. Since then, farmers and fruit growers have been required to obtain licences from the NSW National Parks and Wildlife Service (NPWS) in order to shoot flying foxes to protect their crops (Waples 2002). Licences are granted only when a NPWS representative has visited the orchard to inspect and assess whether the damage is severe enough to warrant culling (Comensoli 2002). Each licence allows a maximum of 50 flying foxes to be shot, and no more than two licences can be granted per landowner per season. Licence holders are required to submit reports on actual numbers of flying foxes killed (Waples 2002). However, in practice, this licensing system is far from perfect, as compliance monitoring and enforcement are neither practical nor feasible, and therefore, records can be unreliable (McLachlan 2002; Waples 2002; Thiriet 2010).

In 2001, the NSW government changed the listing of the grey-headed flying fox (Pteropus poliocephalus) from Protected to Vulnerable under the NSW Threatened Species Conservation Act 1995 (Eby and Lunney 2002). This resulted in negative reactions from the commercial fruit industry (e.g. Biel 2002; Bicknell 2002; Bower 2002; Comensoli 2002; Thiriet 2010), as it meant that even if shooting of the threatened species were still permitted for crop protection, it would be subject to a tighter licensing system, resulting in socio-economic repercussions, particularly for small growers (Bower 2002; Comensoli 2002; Ullio 2002; Waples 2002). The state government subsequently continued to allow shooting of the species for crop protection (Thiriet 2010). However, at the time of writing, the NSW government has now banned shooting of flying foxes as an orchard control method (G. Richards, unpublished).

In July 2011, in order to eliminate the need to issue shooting licences and to mitigate flying fox damage to crops, the NSW government introduced a AUD 5 million scheme to subsidise the cost of installing netting for commercial orchardists in the Sydney Basin and Central Coast regions, where impacts occur 
every year. Once a netting subsidy has been received, the orchardist is no longer eligible for a shooting licence for the netted area of the property. Subsidies are intended to meet half the cost of installing netting and are capped at AUD 20,000 per hectare. Orchardists are responsible for all ongoing maintenance and replacement costs. Not only are flying foxes (and parrots) excluded from the fruit crops, but hail damage is also reduced. This often means that the cost of netting is recovered in the season following its installation. Because netting in now subsidised, from July 2015, licences to shoot flying foxes as a crop protection measure will only be issued where damage to orchards is the result of special circumstances (e.g. the orchard is on terrain too steep to net). The issuing of such licences will eventually be phased out.

$P$. poliocephalus and the spectacled flying fox ( $P$. conspicillatus) were listed as Vulnerable under the EPBC Act 1999, in 2001 and 2002, respectively. One year after its federal listing, $P$. poliocephalus was also listed as Vulnerable in the State of Victoria. Neither the little red flying fox (P. scapulatus) nor the black flying fox (P. alecto) is listed as threatened under any Australian legislation, and the State of Queensland has yet to list any flying fox species as threatened (Thiriet 2010).

In 2002, the State of Queensland banned the use of electric shocks for crop protection, though this was on grounds of animal cruelty rather than conservation. Prior to this, orchardists could receive a damage mitigation permit for electrocuting flying foxes on overhead grids. The use of such electric grids to kill a keystone species was later found to be in breach of the EPBC Act 1999 (which had led to the listing of $P$. conspicillatus), although this was construed as a negative impact on the world heritage values of a nearby Wet Tropics World Heritage Area rather than a biodiversity conservation issue. Shooting of $P$. poliocephalus and $P$. conspicillatus was still allowed for the purpose of crop protection, with an annual limit of up to $1.5 \%$ of the lowest agreed national population estimate for the species. A quota of 30 animals per orchardist per month was implemented. However, in 2008, the state banned all shooting of flying foxes, again due to concerns over animal cruelty (Thiriet 2010).

In 2012, Queensland reintroduced shooting of flying foxes causing damage to commercial fruit, including $P$. poliocephalus and $P$. conspicillatus. However, shooting quotas for these two species are less than for the little red and black flying foxes, $P$. scapulatus and $P$. alecto. Fruit growers require permits to shoot, which are granted only if they can prove that non-lethal methods of control have failed. Such permits allow the use of shotguns and heavy shot on stationary but not on flying bats. Clear X-ray evidence in Australia (Richards et al. 2012; Divljan et al. 2009) and palpation of lead shot in live and dead bats in Madagascar, the Seychelles (P.A. Racey, unpublished) and Mauritius (V. Tatayah, pers. comm.) reveal that the use of shotguns results in wounding and is inhumane, because death is not instantaneous. Also, Thiriet (2010) pointed out that some bats that are shot may be lactating, and their young left behind in the colony will eventually starve to death. Shotguns were however banned in the Seychelles in the 1970s. The toxic effects of lead shot have been well documented for birds (Mateo 2009), and it is likely to have similar effects in bats. 
In both Queensland and NSW, there has been very little (if any) monitoring by relevant authorities of numbers of bats shot in orchards. The only known scientific study was conducted near Sydney in 2007 (Divljan et al. 2009). Over a 140-day period, a total of 164 dead or injured flying foxes were collected and data were compiled from 136 carcasses. Eighty or so bats per week exceeded the number allowed by permits. The sex ratio was strongly skewed towards females (1:1.73), of which $54(65 \%)$ were lactating at the time. Thirteen of these were shot while carrying their dependent young, while 41 pups would have been left behind in the roost to die. Hence, the total estimate of flying foxes that died due to shooting in the orchard over the two-week period was 205. Collected bats suffered from various injuries, and at least $30 \%$ (44\% including the pups left in the camp) were alive and unattended more than $8.5 \mathrm{~h}$ after shooting (Richards et al. 2012). This is in contravention of the definition of 'humane killing' and the Prevention of Cruelty to Animals Act 1979.

\subsubsection{Cyprus}

In Cyprus, $R$. aegyptiacus was officially declared a pest by the Department of Agriculture in the early 1900s. Destruction campaigns and programs to eradicate the species began in the late 1920s. As in Israel, fumigation of caves also depleted populations of insectivorous bats. In addition, bats were shot, with the government offering free cartridges and payment to participating hunters as well as payment for dead bats. These control campaigns finally ended in 1990 after there were very few bats left (Hadjisterkotis 2006). The species became legally protected after Cyprus law No. 24 of 1988 ratified the Convention on the Conservation of European Wildlife and Habitats. This was made possible when Cyprus became a candidate for European Union membership. As the Convention previously only protected insectivorous bats, in 1993 Cyprus added $R$. aegyptiacus to the EU list of protected bats in Annexes II and IV of the council directive 92/42/EEC on the conservation of natural habitats and of wild flora and fauna (Hadjisterkotis 2006).

\subsubsection{Israel}

In Israel, two laws protect animals outside nature reserves or national parks. 'The law for the protection of wild animals' concerns hunting and is considered to be stronger legislation than 'The law for the protection of natural values'. The former aims mainly to regulate hunting (what, how and where?) and lists all protected mammals, including some non-local species. The second law aims to protect aniChironax melanocephalus are listed asmals, plants, fossils and speleothems.

$R$. aegyptiacus is protected by neither law and is considered a pest. Although it is legal to kill fruit bats, cruel killing is forbidden by the 'Animal welfare act'. 
Fruit bat colonies are protected in national parks and nature reserves, but if the bats' foraging sites are outside protected areas, then they may be legally killed.

Israeli conservationists have had protracted negotiations with the Ministry of Agriculture regarding Israel joining the EUROBATS agreement. Although that is likely to happen in the near future, a derogation will be sought to maintain the pest status of R. aegyptiacus, at least for the immediate future (A. Streit, pers. comm.).

\subsubsection{Japan}

Pteropus dasymallus is one of the only two pteropodid species found in Japan, and as such, it is protected at both national and prefectural levels. Both the Daito (P. dasymallus daitoensis) and Erabu (P.d. dasymallus) subspecies are listed as critically endangered (CR) on the IUCN Red List, but P.d. inopinatus and P.d. yayeyamae are not even listed, and the latter two subspecies are only considered as NT in prefectural assessments (Vincenot et al. 2015).

Despite a severe lack of data on the population and conservation status of this species, the IUCN identified its threats only as habitat destruction, electrocution on power cables and occasional accidental entanglement in nets (Heaney et al. 2008). Yet Vincenot et al. (2015) have uncovered evidence of conflict between P.d. yayeyamae and humans on all fruit production islands in the Yaeyama archipelago that they visited. The only island without conflict, Kuroshima, focuses on cattle production instead. This conflict has led to severe declines in flying fox populations throughout the archipelago. It is likely that a similar situation occurs on Okinawa Island, where P.d. inopinatus occurs, as there is higher urbanisation and more agricultural fields there, and crop destruction by flying foxes was reported there in a 2013 Japanese-language news article. In the light of this new evidence, the conservation status of this species needs to be carefully reassessed, with population monitoring and conservation programmes being clearly necessary requirements.

\subsubsection{Malaysia}

In Malaysia, wildlife is governed under three distinct legislative systems according to the three main geopolitical regions: Peninsular Malaysia, Sabah and Sarawak. Protection of the country's two species of flying fox (P. hypomelanus and $P$. vampyrus) varies within and across each of the main geopolitical regions. In Peninsular Malaysia, the Department of Wildlife and National Parks (also known as PERHILITAN) regulates wildlife policy and hunting. For nearly 40 years, wildlife conservation policy was determined by the Protection of WildLife Act of 1972, which listed both flying fox species under Schedule II, or Protected Wild (Game) Animals. Hunting of both species is allowed with a 
permit, and there are no seasons or limits to the numbers of permits that may be issued by a state in Peninsular Malaysia. In 1990, under the Protection of Wild Life Amendment Order, a bag limit was set that allowed 50 bats to be shot under a single permit and the time of hunting was limited to 0700-1200 h and 0500 0700 h each day. Each licence costs MYR 25 (USD 8) (Teoh 2005). No other bats are listed. As in Australia, such a licensed hunting system is difficult to monitor and regulate.

A study by Epstein et al. (2009) evaluated the abundance and roost distribution of $P$. vampyrus in Peninsular Malaysia, finding that the number of hunting licences issued had doubled since 1996, and concluded that current levels were unsustainable and likely to cause local extinction within 6-81 years. Further, these estimates of hunting pressure from licence data were likely to be an underestimate as they did not include illegal hunting, and there was also a provision in the 1972 Act that allowed killing, shooting or removal of an unspecified number of any wild animal that is 'causing damage or there is reason to believe that it is about to cause serious damage to crops, vegetables, fruit, growing timber...if reasonable efforts to frighten away the wild animal have failed'.

The study by Epstein et al. (2009) was highlighted in the media (Burns 2009; Kandasamy 2009) and prompted a response from PERHILITAN that they would consider implementing a hunting ban as part of the then current review of the act. However, when the act was repealed in 2010 by the new Wildlife Conservation Act 2010 (Act 716), flying foxes had still not been moved from the 'Protected' list to the 'Totally Protected' list, meaning that licensed hunting is still permitted, and the provision for protecting crops (Part VI, sec 54) is also still permitted in the new legislation.

In February 2012, following lobbying and recommendations from conservation research group Rimba, the Terengganu state government implemented a state-wide moratorium on hunting of flying foxes (Rimba 2012). Prior to this, the State of Johor had banned hunting of all wildlife when its Sultan issued a royal decree to this effect (Charles and Benjamin 2010). However, to date, no nation-wide hunting ban has been announced by PERHILITAN at the federal level, and other bat species remain unprotected.

As in Peninsular Malaysia, in Sabah, the two flying fox species are currently listed under Schedule 3, sections 2, 25(2) as 'Protected species of animals for which hunting licence is required' under the Wildlife Conservation Enactment of 1997. However, there is no clear provision for shooting animals to protect crops without a licence, and no other bat species are legally protected.

In Sarawak, research by Gumal et al. (1998) successfully resulted in all bat species in the state being listed as 'Protected' in May 1998, under Part II of the Sarawak Wildlife Ordinance 1998 (with the exception of Cheiromeles torquatus that is listed in Part I, as 'Totally Protected'). The Sarawak Forest Department does not allow legal bat hunting and has implemented some of the strictest policies in Malaysia to regulate guns and ammunition and decrease the extent of wildlife poaching. 


\subsubsection{Mauritius and Madagascar}

In 2006, the government of Mauritius proposed changes in legislation to allow culling of the only pteropodid on the island, the endemic P. niger, as a result of losses of marketable fruit, principally lychees. Any effect of this change was confounded, however, by existing legislation that prohibited the discharge of firearms after dark or with the aid of lights, and in the event, in one year, only six bats were officially killed. The proposal to cull an endemic species (albeit only in fruit orchards) on an island where two species (small Mauritian flying fox $P$. subniger and Rodrigues flying fox $P$. rodricensis) had already become extinct as a result of cyclones, habitat loss and overhunting was a major factor in the upgrading of the Red List status of P. niger in 2008 from Vulnerable to Endangered. Pressure on the government from growers of commercial fruit, particularly lychees, but also longans and mangoes, resulted in surveys of bat numbers by the National Parks and Conservation Service (NPCS). In November/December 2010, 49-56,000 bats were counted at 47 roost sites. This was broadly consistent with the results of an earlier count by Robyn (2007) of 12-16,000 bats at 24 of 57 known roosts. As a result, the Red List status of $P$. niger was downgraded from Endangered to Vulnerable in 2013.

Despite assurances from NPCS that there were no plans to cull bats, the National Terrestrial Diversity and National Parks bill was being considered by parliament in May 2012 and has been the subject of a public consultation. It allows for the culling of species that have attained high numbers and pest status. Irrespective of this, the Mauritian Wildlife Foundation, the main conservation NGO on the island, reports that up to 2000 bats are shot annually by hunters and fruit growers.

In Madagascar, bats are 'animaux gibiers,' i.e. game animals, and can be hunted legally although there is a close season coinciding with pregnancy and lactation. Officially, licences are required by hunters, but in practice, this is not usually observed, as enforcement is challenging to implement. Some hunters observe the close season (P.A. Racey, unpublished).

\subsubsection{South Asia}

In India, all pteropodid species with the exception of the Critically Endangered Latidens salimalii are categorised as vermin and included as such in Schedule V of the Indian Wildlife (Protection) Act 1972 and Amended Acts. However, only three of the thirteen species-P. giganteus, R. leschenaultii and C. sphinx-feed extensively on commercial fruit, and the remaining ten species forage mainly in forest where they play an important role in pollination and seed dispersal, and there is no evidence that they visit commercial orchards. The Indian government has ignored successive attempts by conservationists to have forest bats delisted (Singaravelan et al. 2009). 
In Bangladesh, the newly revised Wildlife Preservation and Security Act 2012 protects all species of bats. Hunting is prohibited without government permission and a licence, and offenders can face imprisonment and/or a fine (Act translated from Bengali by A. Islam, pers. comm.).

In Pakistan, P. giganteus is listed in the fourth schedule of the Punjab Wildlife (Protection, Preservation, Conservation and Management) Act 1974, which specifically includes animals that have no legal protection and can be hunted.

In Sri Lanka, the Fauna and Flora Protection Ordinance 1937 (amended 2009) provides protection for all bat species in the country, and hunting is strictly prohibited. Bat roosts such as caves are not currently protected, but the Department of Wildlife Conservation is currently in discussion to protect such sites as refuges by law (W. Yapa, pers. comm.).

\subsubsection{Thailand}

In Thailand, all species of Pteropus (P. hypomelanus, $P$. intermedius, P. lylei, $P$. vampyrus), nectarivorous bats (E. spelaea, Macroglossus minimus and $M$. sobrinus) and Chironax melanocephalus are listed as 'protected animals' under the Wildlife Protection and Reservation Act 1992. Another 13 bat species found in Thailand, including all Cynopterus and Rousettus, are not protected. However, all animals are protected within designated areas, which include national parks, wildlife sanctuaries, and religious establishments (temples, mosques).

Out of a population of 38,000 bats forming 16 colonies of $P$. lylei in central Thailand, $90 \%$ (13 colonies) are found in temples (Boonkird and Wanghongsa 2004), and thus their roosting colonies are well protected. In contrast, most known colonies of $P$. vampyrus and P. hypomelanus are found outside protected areas and therefore suffer from hunting and roost disturbance, except for colonies on oceanic islands. Generally, due to cheaper prices and greater abundance of fruit crops in Thailand, along with smaller population sizes of flying foxes, Pteropus spp. are less likely to be regarded as crop pests. However, smaller fruit bats such as Cynopterus spp. and Rousettus spp. are common and are still regarded as pests. Hunting and selling of flying foxes is widely known to be illegal. Attempts should be made to protect roosting sites outside designated protected areas.

\subsection{Non-lethal Methods of Mitigation}

\subsubsection{Netting and Associated Tree Management}

The only demonstrably effective method of preventing loss of fruit to bats and birds is full exclusion netting. The country in which this has been deployed to the greatest extent and most successfully is Australia where some large fruit orchards 
are enclosed in nets supported by cables, frames or posts (Minifie and Willis 1990; Campbell and Greer 1994; Gough 1992; Stacey 1992; Hall and Willis 1992). The netting has a mesh size of about $48 \mathrm{~mm}$, is erected well above the height of the trees and is also attached to the ground at the edges (Fig. 13.1). Such orchards extend to 90 ha in area (G.C. Richards, unpublished), and the nets protect the crops from bats, other mammals (including possums), birds and hail. Estimates of the cost per hectare of netting vary widely from AUD 6,000 (from a conservationist) to AUD 60,000 (from a fruit grower) (Don't Shoot Bats 2013). Several

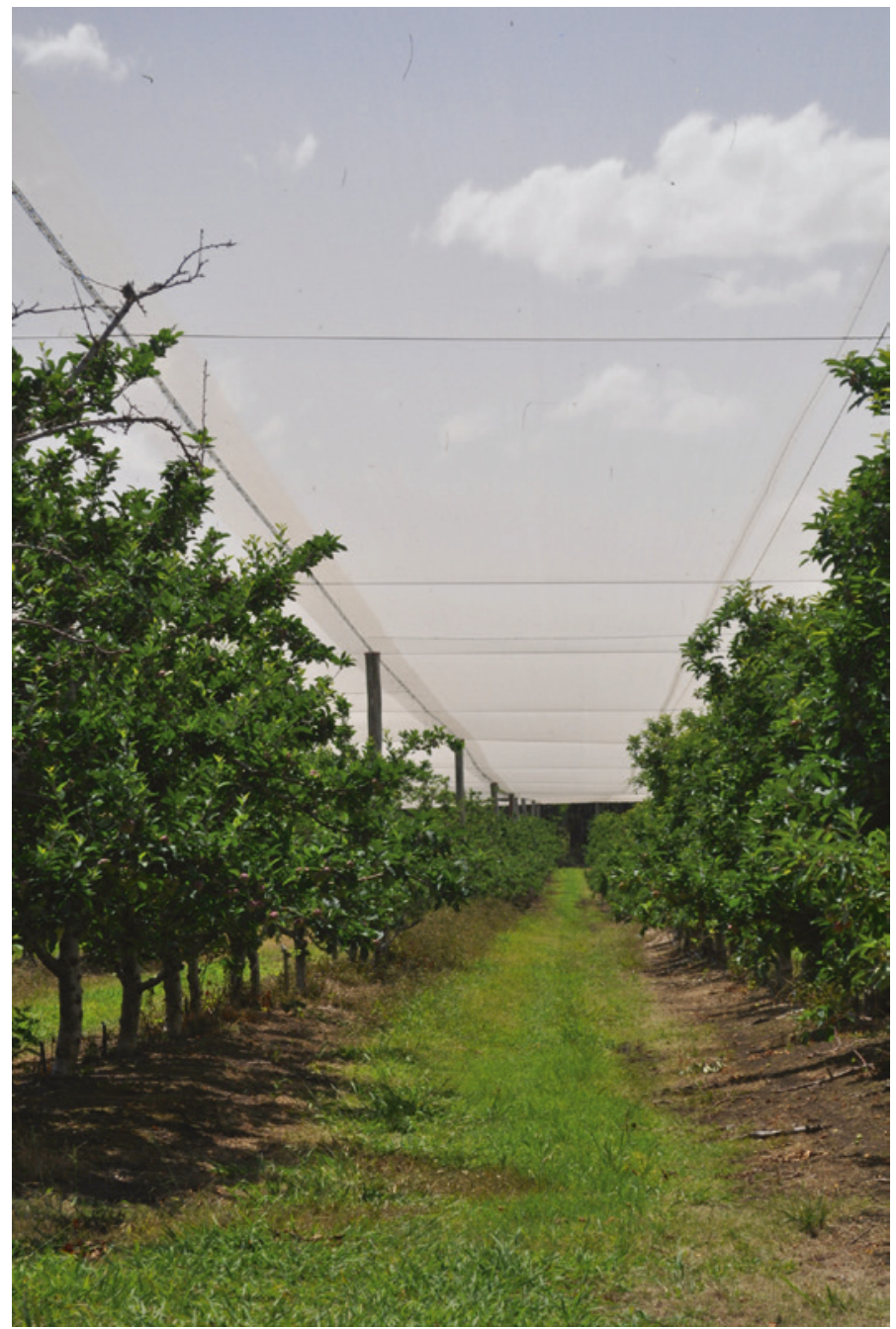

Fig. 13.1 Nets supported by frames in Australia over apples and stone fruit (Photograph Greg Richards) 
state governments now subsidise the erection of netting for orchardists, and most of those interviewed considered that the structures pay for themselves at the first harvest.

But while netting may work for some, issues remain with its implementation in Australia, resulting in poor uptake among some growers (Gough 2002; Ullio 2002). Exclusion netting is costly and thus may not be economically feasible, particularly for smallholdings when flying fox damage is inconsistent and unpredictable from year to year (Slack 1990; Tidemann et al. 1997; Bower 2002; Gough 2002; McLachlan 2002; Rogers 2002; Ullio 2002). Many growers are reluctant to take on this added financial burden and are unlikely to net their crops (Ullio 2002). Bicknell (2002) pointed out that the financial cost of maintaining netting is too great, and it brings an added risk as a fire hazard. Comensoli (2002) further stated that the annual cost of leasing finance for netting outweighed the actual cost of flying fox damage to his crops. He and Ullio (2002) also pointed out that netting creates a microclimate within the orchard that results in poor fruit yield and inferior fruit quality - an experience echoed by other growers, with at least one case of netting in a lychee orchard resulting in a fungal disease (Bicknell 2002).

However, many orchards can be netted as long as they qualify for a state government subsidy, which is often $50 \%$ of the cost. For example, the netted orchard shown in Fig. 13.1 was able to recover its costs at least by the second season, and with 18 ha (40 acres) now protected not just from bats, but also birds and hailstones, it produces top-quality fruit at high prices and with an environmentallyfriendly tag. It used to be thought that because flying fox damage was sporadic and netting might have detrimental effects on crop growth, permanently netting an orchard was not viable for some orchards (Comensoli 2002; Rogers 2002; Ullio 2002). However, now that the industry has settled on a mesh size of $48 \mathrm{~mm}$, so insect pollinators can freely access fruit trees, detrimental effects are no longer reported.

Netting is still not suitable for the banana industry, where plantations are often located on steep slopes that are impossible to net (Bower 2002; Rogers 2002; McLachlan 2002). In some cases, farmers who cannot afford to net have been forced out of business by heavy losses to flying foxes and other frugivores (Rogers 2002). This industry should investigate specific options and provide research funding for trials of innovative ideas, such as solar-powered ripening bags. To ensure that bananas ripen evenly, in Australia each bunch is covered with a plastic bag so that the ethylene by-product is evenly distributed. Once flying foxes smell the ripening aroma, they home in on bunches that they know to be palatable. A solarpowered bag with a low-voltage electric barrier would humanely deter flying foxes, and they would eventually learn not to tear bags open to feed.

A decade after the earlier reports, it is becoming increasingly accepted that netting of orchards is the only method of ensuring their full protection. In Australia, consumer expectations of high-quality fruit are acknowledged by major supermarket chains, so all fruit must be unmarked. Netting that excludes flying foxes, parrots and hail is now considered an industry standard by large producers, so it is only small family orchards that usually do not install nets. Because netting entire orchards is 
expensive (Reilly and Slack 1990), it can only be undertaken when large-scale farming of cash crops makes it cost-effective and justifies the investment.

Commercial crops are also protected by netting in Israel (Korine et al. 1999) and Thailand (Fig. 13.2) (S. Bumrungsri, unpublished), where fixed nets that cover the trees are most effective, although some growers also use mist nets despite their untested efficacy. They are usually lethal to bats, which are not always removed from the nets (C. Korine, pers. comm.). In Thailand, some fruit farmers also erect mist nets in their orchards, leaving tens or hundreds of nectarivorous bats (e.g. E. spelaea) to die (S. Bumrungsri, unpublished).

In some countries, such as Mauritius, entire lychee trees are netted and the government encourages this by subsidising $75 \%$ of the cost of 10 nets per grower. However, individual growers may have 200-300 trees, and the method is applicable only to relatively low-growing orchard trees and not to the much older and larger 'backyard' trees which produce a significant proportion of the national lychee crop.

In Thailand, entire longan trees or groups of trees are covered by either plastic sheets or netting and the former also accelerate ripening (Fig. 13.3) (S. Bumrungsri, unpublished). Farmers actively prune these trees after harvesting, in order to maintain their low stature so that the trees are easily covered with netting during the next fruiting season. A cheaper method of mitigation used in

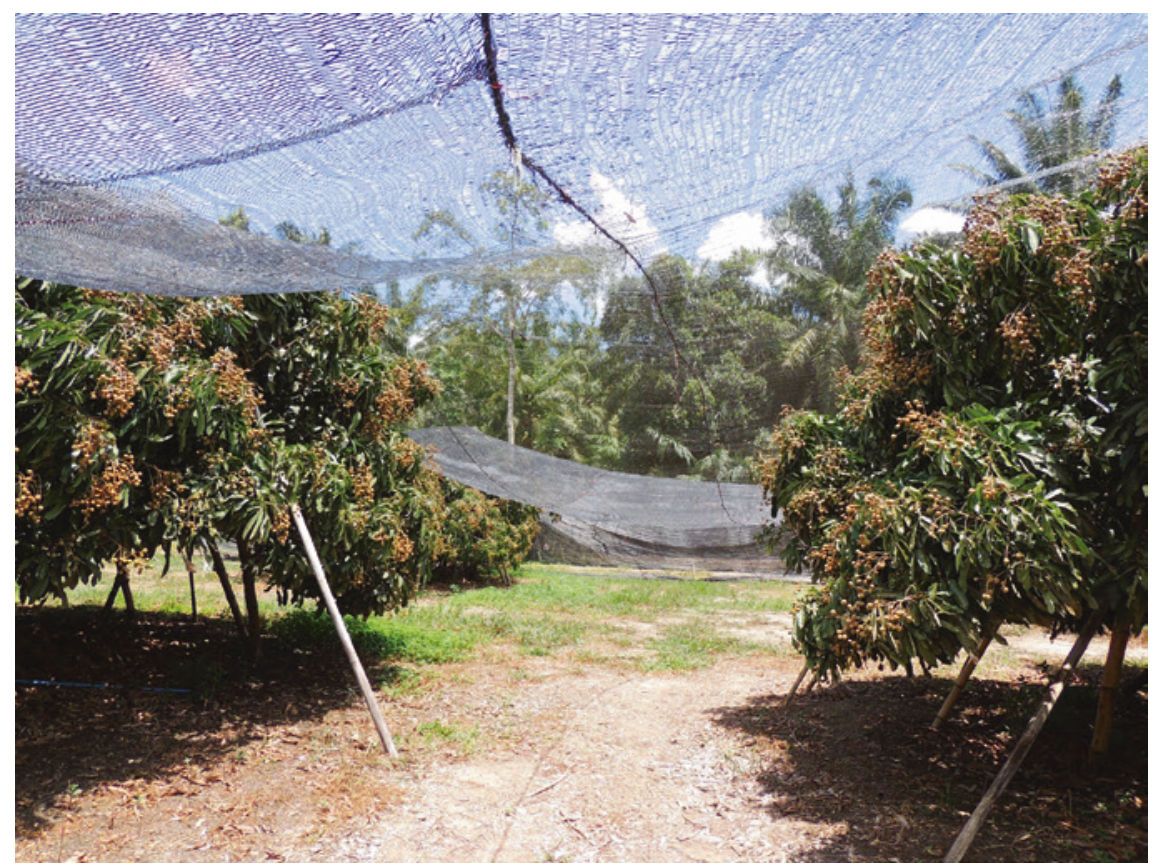

Fig. 13.2 Netted longan orchard in Thailand (Photograph Sara Bumrungsri) 


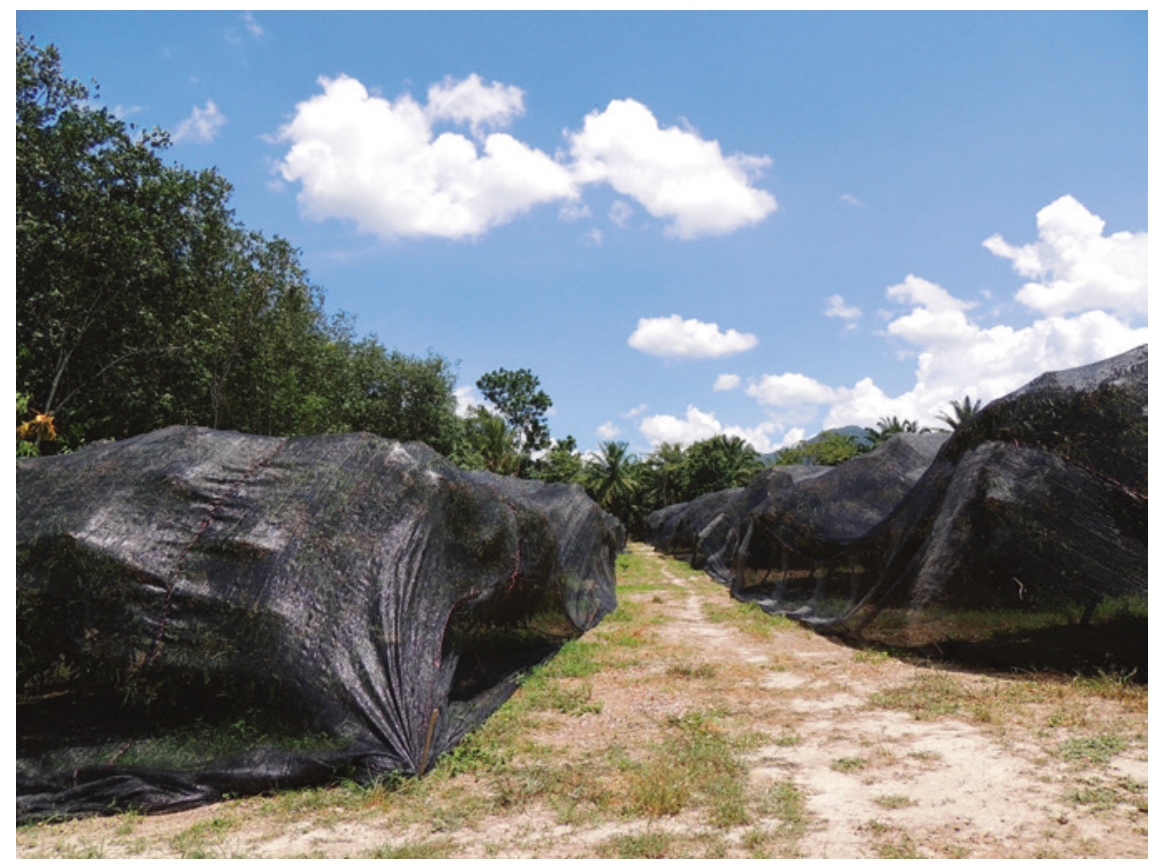

Fig. 13.3 Longan trees covered by nets in Thailand (Photograph Sara Bumrungsri)

Mauritius and Cambodia involves the use of panicle nets consisting of small net bags commonly used to package vegetables, which are of an appropriate size to fit over an immature lychee panicle and can be reused from year to year (Fig. 13.4).

In Mauritius, trees are also pruned to make it easier to cover them with nets, but this involves some loss of productivity until they grow new fruit-bearing branches. When new orchards are planted, dwarf varieties are recommended (as bats prefer feeding on taller trees) and trees are now more widely spaced and are kept pruned to a height that facilitates the deployment of panicle or whole-tree nets. This lowers fruit production for the first three fruiting seasons, but production increases after that. When nets are supported by frames or poles, trees must also be pruned so that they do not grow into the net. This active pruning technique can also be applied to rambutan and lychee. Some nets are removed at the end of the fruiting season and replaced at the beginning of the next. However, most growers leave the nets in place for several seasons (V. Tatayah, pers. comm.).

Much fruit is picked before it has fully ripened and becomes attractive for flying foxes. Mango farmers in north Queensland stated in interviews (G.C. Richards, unpublished) that they harvested their crop just at the onset of ripening, well before it became soft enough to be highly attractive to bats. As well as being too hard to bruise during transport to markets as a high-quality product, there was negligible loss to the growers. By the time flying fox raids began to increase, the remaining crop was high on the trees and difficult to harvest and was left for wildlife. 


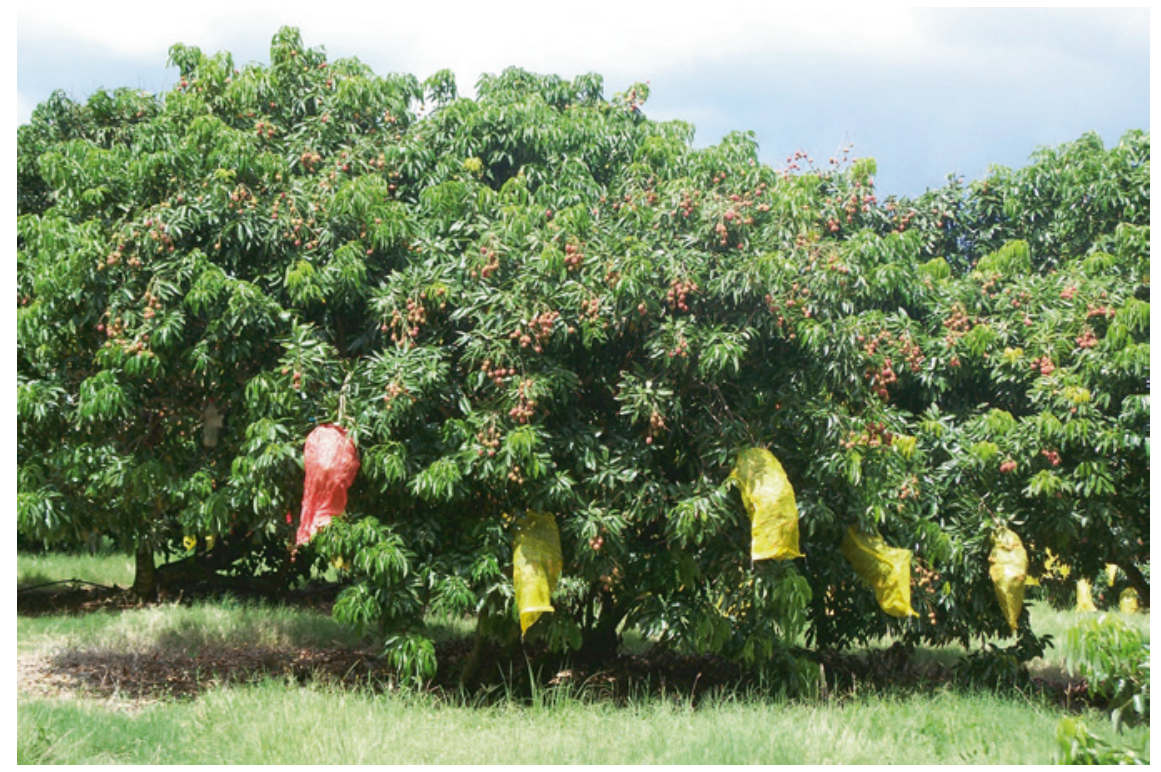

Fig. 13.4 Net bags enclosing lychee panicles in Mauritius (Photograph Vikash Tatayah, Mauritian Wildlife Foundation)

In Bangladesh, a simple cost-effective method is used to prevent bats (including P. giganteus and smaller fruit bats, Cynopterus and Rousettus spp.) and other pests (e.g. birds) from accessing date palm sap during collection. This involves the use of bamboo skirts that cover the top of the collection pot and the shaved part of the palm tree (Nahar et al. 2010) and has been enthusiastically adopted by palm sap collectors (gachhis) (Fig. 13.5). Without it, date palm sap contaminated with bat faeces and urine is of lower quality and value, and, importantly, the risk of Nipah virus transmission is also reduced by using bamboo skirts over collection pots (Nahar et al. 2010).

\subsubsection{Decoy Crops}

A decoy crop produces less valuable or non-commercial fruit which is more attractive to bats than the crop to be harvested. Before selecting a plant species as a decoy crop, the feeding habits and preferences of the bats should be established. There have been many relevant studies. For example, in the Indian Ocean, Racey and Nicoll (1984) listed the food plants of the Seychelles flying fox (Pteropus seychellensis), while Nyhagen et al. (2005) did so for P. niger on Mauritius. Bollen and van Elsacker (2002) and Long and Racey (2007) studied the diet of the Madagascan flying fox (Pteropus rufus) in Madagascar and showed that bats feeding within $100 \mathrm{~km}$ of one another shared few food plants. The diet of another 
Fig. 13.5 Bamboo skirt to prevent bats from accessing palm sap in Bangladesh. Photograph JH Epstein/EcoHealth Alliance

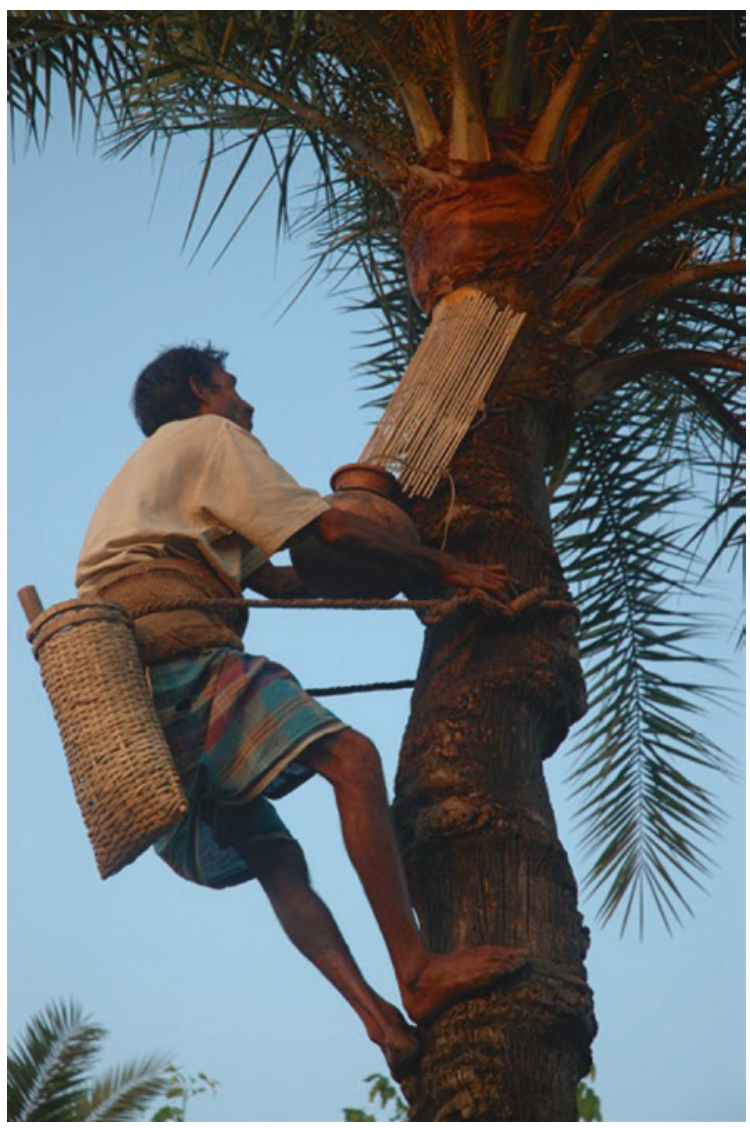

Malagasy endemic Eidolon dupreanum was described by Picot et al. (2007). Stier and Mildenstein (2005) studied the dietary habits of P. vampyrus and Acerodon jubatus in the Philippines. Parry-Jones and Augee (2001) and Williams et al. (2006) investigated food resources and the effect of food availability on the occupation of urban areas by $P$. poliocephalus in Australia, where Richards (1990) also described the diet of $P$. conspicillatus. Bumrungsri et al. (2007) reported on the diet of two species of Cynopterus in Thailand, and Hodgkison et al. (2003, 2004) studied nine fruit bat species in Peninsular Malaysia.

However, only a few studies have sought rigorously to establish feeding preferences: Korine et al. (1998) for $R$. aegyptiacus, Yapa et al. (1999) for $C$. sphinx, Nelson et al. (2005) for the Pacific flying fox (Pteropus tonganus), and Andrianaivoarivelo et al. (2012) for the Madagascan rousette (Rousettus madagascariensis). Bats were briefly taken into captivity to assess their fruit preferences. The first study compared fruits preferred by bats with those eaten by birds, and found that while bats ate $100 \%$ of the introduced fruit species they were offered, 
only $14 \%$ of native fruit species offered to them were actually consumed-suggesting that $R$. aegyptiacus only became common in the eastern Mediterranean with the introduction of new cultivated plants (Korine et al. 1998). The second study found that out of three different types of fruit offered, guava was the most preferred, followed by sea almond (Terminalia catappa) and mango, with fully ripe fruits being preferred over semi-ripe fruits. It concluded that this provided some support for farmers' claims that bats caused damage to their crops (Yapa et al. 1999). The third study tested fruit choice in relation to nutritional requirements. Flying foxes were found to prefer low-calcium, high-sugar fruits such as papayas, but although sugar was the primary basis for fruit selection, pregnant and lactating females required greater amounts of calcium. However, the flying foxes in this study consistently avoided figs, which are excellent sources of calcium (Nelson et al. 2005). In the last study, bats were found to prefer native and commercially unimportant figs (F. polita), rose apple (Syzygium jambos) and mountain apple (S. malaccense) to the cash crops of lychees and persimmon (Andrianaivoarivelo et al. 2012). These important results provide a perspective on the dietary preferences of pteropodids and should be repeated with other species.

There is convincing evidence that planting Muntingia calabura, which is very attractive to C. sphinx, can lessen the impact of these bats on commercial fruit. Singaravelan and Marimuthu (2006) showed that C. sphinx visited Muntingia more than any other wild or commercial fruit and recommended that it is planted around fruit orchards. Verghese's (1998) study on grapes in India found that less bat damage occurred closer to a mango orchard and suggested that presence of these trees deters the bats from feeding on grapes. However, it may be that the fruit bats simply show a stronger preference for feeding on mangoes (e.g. Ayensu 1974; Mahmood-Ul-Hassan et al. 2010). It would thus be useful to compare the results of Verghese's (1998) study with a similar study in the adjacent mango orchard.

Law et al. (2002) recommended planting trees which fruit in spring in Australia to relieve the flying fox damage suffered by orchardists at that time of year. Although the effectiveness of these decoy crops is yet untested, there is evidence that $P$. poliocephalus will cease consumption of commercial fruit if alternative native foods become available (Eby 1990). However, in order to be effective, the selection of plant species must be based on their high productivity and attractiveness to bats as well as producing fruit at the same time as the commercial crop. Local site conditions must also match the specific needs of the plant in order to ensure optimum growth. Most importantly, these food trees should not be planted in the immediate vicinity of orchards but located away from commercial fruit-growing areas in order to attract the bats away from orchards (Law et al. 2002). The authors also suggest that planting Syzygium around commercial fruit trees may reduce the feeding of bats on the latter. As these planting schemes still need to be tested for effectiveness, Law et al. (2002) suggested monitoring results through regular mapping and identifying dietary changes in the bats. 


\subsubsection{Deterrents/Aversion Agents}

There is some evidence that strong smells such as rotting fish may deter bats from approaching ripening fruit and trials to investigate this are currently under way in Thailand (S. Bumrungsri, unpublished). Bicknell (2002) suggested that smoke could be used as an aversion agent, since it is known among Australian orchardists that it is disliked by flying foxes. On Tioman Island in Malaysia, anecdotal information from local communities relates that people build fires under roost trees in order to smoke out flying foxes, although the efficacy of this method is only temporary as it does not deter them from returning (S.A. Aziz, unpublished).

Over the last 30 years in Australia, deterrents used by fruit growers have included flashing and rotating lights, electronic distress sounds, gas-operated bird scare guns, electric shocks, and smell and taste deterrents. However, most of these are used in isolation and their effectiveness has not been systematically assessed, with results being mixed and most evidence anecdotal (Ullio 2002). A project to trial smell and taste deterrents was carried out by the Queensland Parks and Wildlife Service (QPWS) and the Queensland Flying-fox Consultative Committee (QFCC) in 2000. This involved three different commercial products for repelling animals, but none provided complete protection, and the results were ultimately inconclusive due to the small scale of the testing. A plant secondary compound was also tested, with more promising results, and further trials were planned (Teagle 2002), although the outcome is unknown. Bicknell (2002) considered that shooting to frighten, rather than shooting to kill, could also be an effective method.

A noise deterrent was developed in Australia in the late 1990s that reduced orchard crop losses caused by $P$. conspicillatus and $P$. poliocephalus, which was an adaptation of a bird deterrent known as the 'Phoenix Wailer' (Phoenix Agritech Canada Ltd). In essence, it was a sound system with four stereo channels. Each channel had a speaker in the centre of the crop and another at a corner. Sounds were randomly played on each channel, with the sound appearing to come from the centre of the stereo pair. Pellet scars on wing membranes of a large proportion of flying foxes captured in Australia indicate that they had been targeted using shotguns, and therefore, the deterrent system also reproduced a shooting scenario. Sounds of humans (motorbikes, dogs barking) came from one channel, then randomly from another channel came sounds of shotguns, and then from another the screams of a wounded flying fox. Trials in several fruit-growing areas were successful, but the results were not accepted by the industry, which instead called for government trials although these were not implemented. The fruit-growing industry itself did not support independent trials, so this novel approach to mitigation has not been adopted (G.C. Richards, unpublished).

An ultrasonic repeller (Ultrason-X; Bird-X Inc, Chicago) was ineffective at preventing damage to longan panicles by $P$. niger in Mauritius. A similar device (Sonixgate, Tikod Trade Ltd. Tel-Aviv www.batman.co.il) is used in Israel in 
lychee orchards where it is popular with users, although its effectiveness has not been independently established (C. Korine, pers. comm.). Bomford and O'Brien (1990) reviewed the effectiveness of several sonic deterrent devices in animal damage control, although most tests did not involve bats. They pointed out that the efficacy of ultrasonic deterrents for bats was controversial, and there was no evidence that such devices had practical value. They concluded that broadcasting distress or alarm calls was probably the most promising noise deterrent method.

\subsubsection{Combined Methods of Mitigation}

In India, partially covering vulnerable sections of the canopy of fruit trees, illumination and scaring with noises saved 4.5, 6 and $11 \%$ of the fruits of sapota, respectively (Chakravarthy and Girish 2003). However, the effectiveness of these methods was temporary, and for longer term protection, three methods were recommended: planting non-commercial species of figs attractive to the bats; dividing orchards into smaller plots so that trees may be covered with sprigs of foliage, thatch or nylon net; and covering bunches of grapes with dry sprigs of foliage, netting, use of firecrackers or electric fencing. Also in India, Verghese (1998) found that grapes in vineyards could be protected from bat damage if nylon netting is erected around the trellis-grown bower up to bower height, combined with using twigs and briers to cover canopy gaps in the bower.

A combination of lights, noises and plastic flags is widely used in Mauritius (V. Tatayah, pers. comm.).

\subsubsection{Biological Control Agent-Weaver Ants Oecophylla longinoda}

During an interview survey in Guinea, west Africa, almost half of farmers reported that bats fear the weaver ant Oecophylla longinoda, and more than half appreciate that orchards with abundant weaver ants experience less fruit damage due to the ants' protective role, possibly because bats are repelled by the smell of the ants. However, $40 \%$ of farmers also felt that the weaver ant itself is also a form of pest, as it rolls up leaves and is a nuisance during harvest (Van Mele et al. 2009). Yet this species is considered by entomologists and ecologists to be a potential biological control agent (Van Mele 2008). Lokkers (1990) has also suggested the potential of using weaver ants to reduce fruit damage by bats in Australia. However, this proposed method would require a native weaver ant species and requires further research and field trials. 


\subsection{Recommendations and Issues for Future Consideration}

According to opinions from both conservationists and some orchardists, shooting is not an effective means of mitigating flying fox damage to fruit crops, particularly when animal numbers are high (Hall and Richards 1987a, b; McLachlan 2002; Ullio 2002; Thiriet 2010). Most fruit damage occurs when the bats' native food supply is drastically lowered due to droughts or nectar washout (i.e. when heavy rain washes the nectar off the flowers), and killing does not prevent damage in orchards under high flying fox pressure. Because of the bats' mobility, shooting will not stop bats from foraging, as a continuous stream of animals will move into the site from further afield (Martin and McIlwee 2002). Shooting flying foxes has thus become an unnecessary persecution. Hundreds of thousands have been killed in Australia's east coast, even though for 80 years it has been known to be ineffective.

The most effective method to date for reducing crop loss not just to bats, but also to birds and hailstones, is full exclusion netting. If growers' estimates of orchard losses to animals have some credence, then their exclusion is the most appropriate management option. The implementation of such an effective mitigation measure should thus be explored in other countries that experience problems of bat damage to fruit crops. This requires full cooperation between the fruit industry, relevant managing authorities from the government, scientists and conservationists.

In addition to this, below we summarise some main issues that warrant more detailed attention and action in order to resolve the conflict between pteropodid bats and fruit growers.

\subsubsection{Better Knowledge of Pteropodid Diet and Foraging Preferences}

Studies from Cyprus, Israel, Madagascar and Pakistan have shown that fruit bats prefer native wild fruits compared to commercial fruit crops (Korine et al. 1999; Mahmood-Ul-Hassan et al. 2010; Del Vaglio et al. 2011; Andrianaivoarivelo et al. 2012). These findings can be used as a compelling argument in mitigating conflict with orchardists (Del Vaglio et al. 2011) and to prevent deliberate killing of bats for crop protection. However, examples from Australia, Fiji, India, Japan and Malaysia show that depletion of food resources due to habitat loss can drive flying foxes to feed in fruit orchards (Gumal et al. 1998; Verghese 1998; Tidemann 1999; Nakamoto et al. 2007; Luskin 2010). Any mitigation efforts therefore must ensure that wild food sources continue to be maintained in the long term, and where these have been depleted, tree-planting must be carried out to replenish the loss. This is especially important because Nelson et al. (2000) showed that there are negative nutritional consequences for flying foxes which change their diet from native to agricultural fruits. 
However, Biel (2002) reported that even when much native blossom was available nearby, $P$. poliocephalus still preferred to feed on fruit crops, and Bower (2002) stated that it appears to prefer lychees 'over all naturally available foods'. Rogers (2002) reported that flying foxes on the North Coast of NSW were initially only a problem for the stone fruit, lychee and persimmon industries, but that once more of these orchards started adopting netting, the bats began moving on to bananas, coffee, mandarins and mangoes. This was exacerbated in 1999 and 2000 by a decrease in native food, with McLachlan (2002) reporting a similar issue for the 2000/2001 season. Yet there is some evidence that flying foxes will cease to feed on commercial fruit crops if their native food sources again become available in the wild (Eby 1990; Andrianaivoarivelo et al. 2012). The solution may thus consist of a careful selection of preferred tree species planted in appropriate locations away from fruit orchards (Law et al. 2002). Such methods are as yet unproven and require further trials and research.

\subsubsection{Funding Interventions and Research to Mitigate the Pteropodid-Grower Conflict}

Bicknell (2002) advocated an urgent need for funding research into non-lethal aversion agents to mitigate flying fox damage. Such research funds have not yet been made available in Australia. Individual government authorities have been reluctant to take ownership of the problem, while industry organisations do not view it as an industry-wide issue, as the majority of fruit growers in some parts of the country are not affected. Apart from research into specific mitigation methods, there is also a need to study netted orchards in order to determine the effects of netting - not just on the environment created under the net and on the ripening fruit, but also the implications of excluding other potential pollinators such as birds and insects. Ultimately, however, aversion agents and cheaper methods would be a preferred method for many orchardists in Australia compared to netting or even culling (Ullio 2002), and funds should be provided to develop and test such methods (Bicknell 2002; Bower 2002; Thiriet 2010). Thiriet (2010) also suggested that the dearth of such funding is caused by negative community attitudes and political considerations, which may influence the inaccurate conservation status of some species of flying foxes, such as Least Concern as in Queensland. The unpopularity of these species must thus be overcome in order to attract appropriate research funding.

Australian orchardists maintain that it is the government's responsibility, not theirs, to fund the research (Bicknell 2002) because they believe it was not orchards which caused the habitat loss driving this problem (Tidemann 1999). Bicknell (2002) pointed out that orchards provide flying foxes with food when wild resources are scarce. He also highlighted how government departments are responsible for releasing large areas of flying fox habitat for logging and agriculture and that therefore, the financial burden of protecting crops from flying foxes should be borne by the authorities. Biel (2002) echoed this concept of 'public good conservation', stating that flying fox conservation benefits the wider 
community, and cited examples of other projects that utilised the community benefit approach. He pointed out that the loss of native flying fox food in Australia was caused by 'the people who lived in the cities', since most fruit orchards were established on land that had already been previously cleared for cattle grazing. Fruit growers could thus be said to have revegetated the land, and therefore, it is unfair that they alone should bear the cost of protecting flying foxes. Martin and McIlwee (2002) agree with this and recommend that the cost of netting should be subsidised by federal funding.

\subsubsection{Education of Growers and the Public}

Apart from research into damage mitigation methods, there is also an urgent need to educate fruit growers and increase their awareness on the ecological and economic importance of pteropodid bats. Huang et al. (2014) found that in Sumatra, less than $20 \%$ of coffee growers interviewed $(n=16)$ were aware that bats were pollinators, and none were aware that bats dispersed seeds. As demonstrated by Bumrungsri et al. (2008, 2009), pteropodids are major pollinators for some commercially important fruit trees, even when the bats may not be the most frequent visitors. In northern Queensland, P. conspicillatus plays a vital role in rainforest reproduction through pollination, and although these bats may affect the fruit industry, there has never been a full study of the economic value of flying foxes as pollinators of eucalypt hardwood forests in Australia. The majority of timber trees harvested on the east coast produce nectar and pollen only at night (P. Birt, unpublished). This means that as flying fox populations decrease, fewer timber trees will join the logging cycle.

More importantly, pteropodid bats play a major role in seed dispersal. The further that a fruit is dispersed from the parent tree, the greater the chance of any resulting seedlings surviving to maturity. Fighting over feeding territories (the squabbling heard at night) leads to the loser departing with a fruit in its mouth, and consuming it at a distance. This has been termed the 'raiders versus residents' seed dispersal model (Richards 1990), tested by McConkey and Drake (2006) in Tonga, where they showed that once numbers of flying foxes declined below a threshold where there was no conflict over feeding territories, then seed dispersal away from the parent tree ceased.

Therefore, while economic estimates of fruit loss are an important first step in quantifying the problem of crop damage, a cost-benefit analysis that takes into account the positive economic impact of ecosystem services provided by the same bat species (e.g. pollination and seed dispersal to maintain healthy forests) is needed. The resulting data must be shared and communicated to growers and orchardists. They will form a crucial component in mitigating conflict, as at least one example from an Australian orchardist shows that ignorance can lead to opinions that the ecological role of flying foxes is negligible. The orchardist claimed to have seen no evidence that flying foxes are essential to forests (Bicknell 2002). This shows that in some cases, feeding on fruit crops can create a negative bias 
among fruit growers against the beneficial aspects of bats. Therefore, bat conservation must also extend to educating and raising awareness of the farmers and fruit growers who bear the brunt of bat damage to their crops.

In Australia, NSW Agriculture suggested that in order to address and overcome the conflict between fruit growers and flying foxes, a NSW Flying-fox Consultative Committee should be formed along the lines of the Queensland Flying-fox Consultative Committee (QFFCC). This would include a dedicated Flying-fox Management Unit that would be responsible for population monitoring, community liaison, research and compensation to growers (Bower 2002). The QFFCC's role included providing a forum for multi-stakeholder consultation, providing advice on policy development, developing strategies to address crop damage, and disseminating information to stakeholders (Teagle 2002). This model of collaborative approach involving all interest groups should be adopted in other countries where pteropodid feeding is a serious concern for their respective fruit industries. However, support for this type of consultation is entirely dependent upon the policies of the government of the time. No consultative committees now exist in New South Wales or Queensland, and the government of the latter state actively supports the destruction of flying foxes in orchards.

In the Mascarene Islands, public education programmes about $P$. rodricensis on Rodrigues since 1998 have led to a sense of pride in this species among the inhabitants, despite the fact that the increasing bat population ( $>20,000$ individuals on an island area of $109 \mathrm{~km}^{2}$ ) damages the fruit on backyard trees and causes some discontent. While Rodriguans complain about loss of fruit, they are still tolerant of the bats, as a result of positive messages in schools and communities, and are less inclined to call for culling as a solution to the crop-raiding issue (V. Tatayah, pers. comm.).

\subsection{Conclusions}

Pteropodid bats can reduce the harvestable yield of a wide range of fruit crops, resulting in economic losses that can be severe. However, this problem appears to be caused, and exacerbated, by continuing loss of the bats' natural food, which happens when humans clear natural forests. Lethal methods to reduce fruit crop damage are ineffective and problematic, and thus, the best solution is to implement non-lethal mitigation such as fixed nets, deterrents and decoy trees. In some instances, a combination of some or all of these non-lethal methods may be required. However, further research and trials are required for some of these methods, and these would be aided by ecological research focusing specifically on feeding behaviour and dietary preferences of those pteropodid species implicated in crop damage. In addition, there is an urgent need to educate fruit growers, authorities and the general public about the important benefits and ecosystem services provided by pteropodid bats. Such information may work best when presented in economic terms and measurements, such as cost-benefit analyses, to make it immediately relevant to economies and livelihoods. 
Acknowledgements We are grateful to C. Korine, N. Singaravelan and V. Tatayah for their comments on an earlier draft; to T. Kingston for helpful editing; and to N. Islam, A. Tsoar and W. Yapa for their assistance.

Open Access This chapter is distributed under the terms of the Creative Commons Attribution Noncommercial License, which permits any noncommercial use, distribution, and reproduction in any medium, provided the original author(s) and source are credited.

\section{References}

Albayrak I, Asan N, Yorulmaz T (2008) The natural history of the Egyptian fruit bat, Rousettus aegyptiacus, in Turkey (Mammalia: Chiroptera). Turk J Zool 32:11-18

Amman BR, Jones MEB, Sealy TK et al (2014a) Oral shedding of Marburg virus in experimentally infected Egyptian fruit bats (Rousettus aegyptiacus). J Wildl Dis (ahead of print)

Amman BR, Nyakarahuka L, McElroy AK (2014b) Marburgvirus resurgence in Kitaka mine bat population after extermination attempts, Uganda. Emerg Infec Dis 20(10):1761-1764

Andrianaivoarivelo RA, Jenkins RKB, Petit EJ et al (2012) Rousettus madagascariensis (Chiroptera: Pteropodidae) shows a preference for native and commercially unimportant fruits. Endanger Species Res 19:19-27

Ayensu EA (1974) Plant and bat interactions in West Africa. Ann Mo Bot Gard 61:702-727

Bicknell JR (2002) The need for aversion agents for managing flying-foxes on crops and the difficulties in attracting research funds. In: Eby P, Lunney D (eds) Managing the grey-headed flying-fox as a threatened species in NSW. Royal Zoological Society of New South Wales, Mosman, NSW, pp 63-69

Biel E (2002) The cost to orchardists in the management of the grey-headed flying-fox. Who pays? A community benefit approach. In: Eby P, Lunney D (eds) Managing the grey-headed flying-fox as a threatened species in NSW. Royal Zoological Society of New South Wales, Mosman, NSW, pp 47-52

Bollen A, Van Elsacker L (2002) Feeding ecology of Pteropus rufus (Pteropodidae) in the littoral forest of Sainte Luce, SE Madagascar. Acta Chiropterol 4:33-47

Bomford M, O'Brien PH (1990) Sonic deterrents in animal damage control: a review of device tests and effectiveness. Wildl Soc Bull 18:411-422

Bower C (2002) Management issues in minimisation of damage by flying-foxes to horticultural crops. In: Eby P, Lunney D (eds) Managing the grey-headed glying-fox as a threatened species in NSW. Royal Zoological Society of New South Wales, Mosman, NSW, pp 77-79

Boonkird K, Wanghongsa S (2004) On the population number and distribution of flying foxes (Pteropus lylei) in central plain. In: 2003 Annual Report of Wildlife Research Division. Department of National Parks, Wildlife and Plant Conservation, Bangkok, pp 89-100 (In Thai)

Bumrungsri S, Leelapaibul W, Racey PA (2007) Resource partitioning in sympatric Cynopterus bats in lowland tropical rainforest, Thailand. Biotropica 39:241-248

Bumrungsri S, Harbit A, Benzie C et al (2008) The pollination ecology of two species of Parkia in southern Thailand. J Trop Ecol 24:467-475

Bumrungsri S, Sripaoraya E, Chongsiri T et al (2009) The pollination ecology of durian (Durio zibethinus) in southern Thailand. J Trop Ecol 25:85-92

Burns J (2009) Extinction threat to flying fox. BBC Online, 25 August, http://news.bbc.co.uk/2/ hi/science/nature/8221132.stm. Accessed 5 Nov 2013

Campbell J, Greer N (1994) Controlling pest losses—why, how, how much? In: Bird and bat control for horticulture and aquaculture, Nambour, Queensland, 18 May 1994. Seminar proceedings, Department of Environment and Heritage, Queensland, pp 38-41 
Chakravarthy AK, Girish AC (2003) Crop protection and conservation of frugivorous bats in orchards of hill and coastal regions of Karnataka. Zoos' Print J 18:1169-1171

Charles L, Benjamin N (2010) Ruler bans hunting of wildlife. The Star, 5 March

Chua KB, Koh CL, Hooi PS et al (2002) Isolation of Nipah virus from Malaysian island flyingfoxes. Microb Infect 4:145-151

Clulow S, Blundell AT (2011) Deliberate insectivory by the fruit bat Pteropus poliocephalus by aerial hunting. Acta Chiropterol 13:201-205

Comensoli P (2002) The impact upon fruit growers of a decision to list the grey-headed flyingfox as a Vulnerable species under the NSW Threatened Species Conservation Act. In: Eby P, Lunney D (eds) Managing the grey-headed flying-fox as a threatened species in NSW. Royal Zoological Society of New South Wales, Mosman, NSW, pp 53-55

Del Vaglio MA, Nicolau H, Bosso L et al (2011) Feeding habits of the Egyptian fruit bat Rousettus aegyptiacus on Cyprus island: a first assessment. Hystrix Ital J Mamm 22:281-289

Dewhurst (1998) Correspondence from Queensland Fruit and Vegetable Growers to DPI. Quoted by Teagle $\mathrm{S} 2002$ op cit

Divljan A, Parry-Jones K, Eby P (2009) Report on deaths and injuries to grey-headed flyingfoxes, Pteropus poliocephalus shot in an orchard near Sydney, NSW. Aust Zool 35:698-710

Dolbeer RR, Fiedler LR, Rasheed H (1988) Management of fruit bat and rat populations in the Maldive Islands, Indian Ocean. In: Crabb AC, Marsh RE (eds) Proceedings of the vertebrate pest conference, vol 13, pp 112-118. University of California, Davis

Don't Shoot Bats 2013. Lethal crop protection is not effective. http://www.dontshootbats.com/ crop-protection.html. Accessed 18 November 2013

Eby P (1990) Seed dispersal and seasonal movements by grey-headed flying foxes and the implications for management. In: Slack J (ed) Flying-fox workshop proceedings. Wollongbar Agricultural Institute, Wollongbar, pp 28-32

Eby P (1995) The biology and management of flying foxes in NSW. NSW National Parks and Wildlife Service, Hurstville, NSW

Eby P, Lunney D (2002) Managing the grey-headed flying-fox Pteropus poliocephalus as a threatened species: a context for the debate. In: Eby P, Lunney D (eds) Managing the greyheaded flying-fox as a threatened species in NSW. Royal Zoological Society of New South Wales, Mosman, NSW, pp 1-15

Entwistle AC, Corp N (1997) The diet of Pteropus voeltzkowi, an endangered fruit bat endemic to Pemba Island, Tanzania. Afr J Ecol 35:351-360

Epstein JH, Olival KJ, Pulliam JRC et al (2009) Pteropus vampyrus, a hunted migratory species with a multinational home-range and a need for regional management. J Appl Ecol 46:991-1002

Field H, Young P, Yob JM et al (2001) The natural history of Hendra and Nipah viruses. Microb Infect 3:307-314

Fleming TH, Kress WJ (2011) A brief history of fruit and frugivores. Acta Oecol 37:521-530

Fleming TH, Geiselman C, Kress WJ (2009) The evolution of bat pollination-a phylogenetic perspective. Ann Bot 104:1017-1043

Fogarty R, Halpin K, Hyatt AD et al (2008) Henipavirus susceptibility to environmental variables. Virus Res 132:140-144

Fujita F (1988) Flying foxes and economics. BATS Magazine 6(1). http://www.batcon.org/ index.php/media-and-info/bats-archives.html?task=viewArticle\&magArticleID $=318$. Accessed 3 March 2013

Fujita MS, Tuttle MD (1991) Flying foxes (Chiroptera, Pteropodidae)—-threatened animals of key ecological and economic importance. Cons Biol 5:455-463

Funakoshi K, Watanabe H, Kunisaki T (1993) Feeding ecology of the northern Ryukyu fruit bat, Pteropus dasymallus dasymallus, in a warm-temperate region. J Zool Lond 230:221-230

Galil J, Stein M, Horoviz A (1976) On the origin of the sycamore fig (Ficus sycomorus L.) in the Middle East. Gard Bull XXIX:191-205 
Gough JD (1992) Drift nets of the northern rivers. In: Blade K (ed) Fruit crop protection seminar. NSW National Parks and Wildlife Service, Australia, pp 14-17

Gough J (2002) The increasing need for netting fruit orchards against bat and bird damage and the increasing problems in affording netting. In: Eby P, Lunney D (eds) Managing the greyheaded flying-fox as a threatened species in NSW. Royal Zoological Society of New South Wales, Mosman, NSW, pp 56-57

Groseth A, Feldmann H, Strong JE (2007) The ecology of Ebola virus. Trends Microbiol $15: 408-416$

Gumal MT, Irwan M, Brandah CJ et al (1998) The ecology and role of the large flying fox (Pteropus vampyrus) in Sarawakian rain forests—Keluang embet embet. Hornbill 2:82-95

Hadjisterkotis E (2006) The destruction and conservation of the Egyptian fruit bat Rousettus aegyptiacus in Cyprus: a historic review. Eur J Wildl Res 52:282-287

Hall LS, Richards GC (1987a) Crop protection and management of flying-foxes (Chiroptera: Pteropodidae). Aust Mammal 10:137-139

Hall LS, Richards GC (1987b) The flying-fox problem in eastern Australia. In: Proceedings of the 1987 Australian vertebrate pest control conference, Coolangatta, pp 279-283

Hall J, Willis B (1992) Netting orchards against flying foxes, birds and hail. In: Blade K (ed) Fruit crop protection seminar. NSW National Parks and Wildlife Service, Australia, pp 24-28

Halpin K, Young PL, Field HE, Mackenzie JS (2000) Isolation of Hendra virus from pteropid bats: a natural reservoir of Hendra virus. J Gen Virol 81:1927-1932

Harrison DL (1964) The Mammals of Arabia. Insectivora, Chiroptera, Primates. Ernest Bern Limited, London

Harrison DL, Bates PJJ (1991) The Mammals of Arabia. Harrison Zoological Museum, 2nd edn. Lakeside Printing, London

Harrison ME, Cheyne SM, Darma F et al (2011) Hunting of flying foxes and perceptions of disease risk in Indonesian Borneo. Biol Cons 144:2441-2449

Heaney L, Rosell-Ambel G, Tabaranza B et al (2008) Pteropus dasymallus. IUCN Red List of Threatened Species. Version 2015.3. http://www.iucnredlist.org. Accessed 25 July 2015

Hicks PG (1967) Observations on the diseases and conditions of cocoa pods in Papua and New Guinea-Pod losses 1962-1965. P N G Agr J 19:5-9

Hodgkison R, Balding ST, Zubaid A et al (2003) Fruit Bats (Chiroptera: Pteropodidae) as seed dispersers and pollinators in a lowland Malaysian rain forest. Biotropica 35:491-502

Hodgkison R, Balding ST, Zubaid A et al (2004) Temporal variation in the relative abundance of fruit bats (Megachiroptera: Pteropodidae) in relation to the availability of food in a lowland Malaysian rain forest. Biotropica 36:522-533

Huang JC-C, Jazdzyk E, Nusalawo M, et al (2014) Is Bat coffee a potential "wing-wing" tool for biodiversity conservation in southwestern Sumatra? Paper presented at the 16th international bat research conference, Hotel Herradura, San José, 11-15 Aug 2013, Bat Res News (in press)

IUCN (2014) IUCN Red List of Threatened Species. Version 2014.2. http://www.iucnredlist.org. Accessed 10 Nov 2014

Izhaki I, Korine C, Arad Z (1995) The effect of bat (Rousettus aegyptiacus) dispersal on seed germination in eastern Mediterranean habitats. Oecologia 101:335-342

Kandasamy D (2009) Flying foxes facing extinction. The Malay Mail, 2 Sept

Khan MSU, Hossain J, Gurley ES et al (2011) Use of infrared camera to understand bats' access to date palm sap: implications for preventing Nipah virus transmission. EcoHealth 7:517-525

Kingston T (2010) Research priorities for bat conservation in Southeast Asia: a consensus approach. Biodivers Conserv 19:471-484

Korine C, Izhaki I, Arad Z (1998) Comparison of fruit syndromes between the Egyptian fruit-bat (Rousettus aegyptiacus) and birds in East Mediterranean habitats. Acta Oecol 19:147-153

Korine C, Izhaki I, Arad Z (1999) Is the Egyptian fruit-bat Rousettus aegyptiacus a pest in Israel? An analysis of the bat's diet and implications for its conservation. Biol Cons 88:301-306

Kunz TH, de Torrez EB, Bauer D et al (2011) Ecosystem services provided by bats. Ann NY Acad Sci 1223:1-38 
Lane DJW, Kingston T, Lee BPY-H (2006) Dramatic decline in bat species richness in Singapore, with implications for Southeast Asia. Biol Cons 131:584-593

Law B, Eby P, Somerville D (2002) Tree-planting to conserve flying-foxes and reduce orchard damage. In: Eby P, Lunney D (eds) Managing the grey-headed flying-fox as a threatened species in NSW. Royal Zoological Society of New South Wales, Mosman, NSW, pp 84-90

Lee Y-F, Takaso T, Chiang T-Y et al (2009) Variation in the nocturnal foraging distribution of and resource use by endangered Ryukyu flying foxes (Pteropus dasymallus) on Iriomotejima Island, Japan. Contr Zool 78:51-64

Leroy EM, Rouquet P, Formenty P et al (2004) Multiple Ebola virus transmission events and rapid decline of central African wildlife. Science 303:387-390

Leroy EM, Kumulungui B, Pourrut X et al (2005) Fruit bats as reservoirs of Ebola virus. Nature 438:575-576

Leroy EM, Epelboin A, Mondonge V et al (2009) Human Ebola outbreak resulting from direct exposure to fruit bats in Luebo, Democratic Republic of Congo, 2007. Vector-Borne Zoonotic Dis 9:723-728

Lewis RE, Harrison DL (1962) Notes on bats from the Republic of Lebanon. Proc Zool Soc Lond 138:473-486

Lobova TA, Geiselman CK, Mori SA (2009) Seed dispersal by bats in the neotropics. New York Botanical Garden, New York (Mem New York Bot Gard 101)

Lokkers C (1990) Colony dynamics of the green tree ant (Oecophylla smaragdina Fab.) in a seasonal tropical climate. PhD dissertation, James Cook University

Long E, Racey PA (2007) An exotic plantation crop as a keystone resource for an endemic megachiropteran, Pteropus rufus in Madagascar. J Trop Ecol 23:1-11

Luby SP, Rahman M, Hossain MJ et al (2006) Foodborne transmission of Nipah virus, Bangladesh. Emerg Infect Dis 12:1888-1894

Lumlertdacha B, Boongird K, Wanghongsa S et al (2005) Survey for bat lyssaviruses, Thailand. Emerg Infect Dis 11:232-236

Luskin MS (2010) Flying foxes prefer to forage in farmland in a tropical dry forest landscape mosaic in Fiji. Biotropica 42:246-250

Mackenzie JS, Field HE, Guyatt KJ (2003) Managing emerging diseases borne by fruit bats (flying foxes), with particular reference to henipaviruses and Australian bat lyssavirus. J Appl Microbiol 94:59S-69S

Madkour G (1977) Rousettus aegyptiacus (Megachiroptera) as a fruit eating bat in A.R. Egypt. Agric Res Rev 55:167-172

Mahmood-Ul-Hassan M, Gulraiz TL, Rana SA et al (2010) The diet of Indian flying-foxes (Pteropus giganteus) in urban habitats of Pakistan. Acta Chiropterol 12:341-347

Makin D, Mendelssohn H (1987) Israel wipes out its bats. Ecologist 16:1-2

Marshall AG (1983) Bats, flowers and fruit: evolutionary relationships in the Old World. Biol J Linn Soc 20:115-135

Martin L, McIlwee AP (2002) The reproductive biology and intrinsic capacity for increase of the grey-headed flying-fox Pteropus poliocephalus (Megachiroptera), and the implications of culling. In: Eby P, Lunney D (eds) Managing the grey-headed flying-fox as a threatened species in NSW. Royal Zoological Society of New South Wales, Mosman, NSW, pp 91-108

Mateo R (2009) Lead poisoning in birds in Europe and the regulations adopted by different countries. In: Watson RT, Fuller M, Pokras M et al (eds) Ingestion of lead from spent ammunition: implications for wildlife and humans. The Peregrine Fund, Boise, Idaho, pp 71-98

Meyer C, Struebig M, Willig M (in press) Responses of tropical bats to habitat fragmentation, logging and deforestation. In: Kingston T, Voigt CC (eds) Bats in the anthropocene. Springer, New York, pp 63-94

McConkey KR, Drake DR (2006) Flying foxes cease to function as seed dispersers long before they become rare. Ecology 87:271-276

McLachlan B (2002) NPWS operational management of commercial crop damage by flyingfoxes-licensing in practice, a far north coast perspective. In: Eby P, Lunney D (eds) Managing the grey-headed flying-fox as a threatened species in NSW. Royal Zoological Society of New South Wales, Mosman, NSW, pp 80-83 
Mickleburgh S, Hutson AM, Racey PA (1992) Old World Fruit Bats-an action plan for their conservation. IUCN, Gland

Mickleburgh S, Waylen K, Racey PA (2009) Bats as bushmeat-a global review. Oryx 43:217-234

Minifie G, Willi B (1990) Duranet cloth and supporting systems. In: Slack JM (ed) Flying fox workshop proceedings, Wollongbar Agricultural Institute, Wollongbar. NSW Agriculture and Fisheries, Australia, pp 47-55

Moran S, Keidar H (1993) Checklist of vertebrate damage to agriculture in Israel. Crop Prot 12:171-182

Myers N, Mittermeier RA, Mittermeier CG et al (2000) Biodiversity hotspots for conservation priorities. Nature 403:853-858

Nahar N, Sultana R, Gurley ES et al (2010) Date palm sap collection: exploring opportunities to prevent Nipah transmission. EcoHealth 7:196-203

Nakamoto A, Kinjo K, Izawa M (2007) Food habits of Orii's flying-fox, Pteropus dasymallus inopinatus, in relation to food availability in an urban area of Okinawa-jima Island, the Ryukyu Archipelago, Japan. Acta Chiropterol 9:237-249

Nakamoto A, Kinjo K, Izawa M (2009) The role of Orii's flying-fox (Pteropus dasymallus inopinatus) as a pollinator and seed disperser on Okinawa-jima Island, the Ryukyu Archipelago, Japan. Ecol Res 24:405-414

Nelson SL, Miller MA, Heske EJ et al (2000) Nutritional consequences of a change in diet from native to agricultural fruits for the Samoan fruit bat. Ecography 23:393-401

Nelson SL, Masters DV, Humphrey SR et al (2005) Fruit choice and calcium block use by Tongan fruit bats in American Samoa. J Mammal 86:1205-1209

Nyhagen DF, Turnbull SD, Olesen JM et al (2005) An investigation into the role of the Mauritian flying fox, Pteropus niger, in forest regeneration. Biol Cons 122:491-497

Oleksy R, Racey PA, Jones G (2015) High-resolution GPS tracking reveals habitat selection and the potential for long-distance seed dispersal by Madagascan flying foxes Pteropus rufus. Glob Ecol Conserv 3:678-692

Olival KJ, Hayman DTS (2014) Filoviruses in Bats: current knowledge and future directions. Viruses 6:1759-1788

Parry-Jones KA, Augee ML (2001) Factors affecting the occupation of a colony site in Sydney, New South Wales by the grey-headed flying-fox Pteropus poliocephalus (Pteropodidae). Aust Ecol 26:47-55

Phillips WWA (1980) Manual of Mammals of Sri Lanka (Part 1). Wild Life and Nature Protection Society of Sri Lanka

Picot M, Jenkins RBK, Ramilijoana O et al (2007) The feeding ecology of Eidolon dupreanum (Pteropodidae) in eastern Madagascar. Afr J Ecol 45:645-650

Price V (2013) Trouble in paradise: mapping human-wildlife conflict in the western Indian Ocean. Unpublished MSc thesis, Imperial College, London, UK

Qumsiyeh MB (1980) New records of Bats from Jordan. Säugetierkd Mitt 1:36-39

Qumsiyeh MB, Disi AM, Amr ZS (1992) Systematics and distribution of the bats (Mammalia: Chiroptera) of Jordan. Dirasat 19B:101-118

Racey PA, Nicoll ME (1984) Mammals. In: Stoddart DR (ed) Biogeography and ecology of the Seychelles Islands. Dr W Junk, The Hague, pp 607-626

Rahman MA, Hossain MJ, Sultana S et al (2012) Date palm sap linked to Nipah virus outbreak in Bangladesh, 2008. Vector-Borne Zoonotic Dis 12:65-72

Rahman SA, Hassan L, Epstein JH et al (2013) Risk factors for Nipah virus infection among pteropid bats, Peninsular Malaysia. Emerg Infect Dis 19:51-60

Ramlugun TMRRS (2013) An assessment of fruit bat damage caused by the Mauritian fruit bat (Pteropus niger) in a litchi (Litchi chinensis) orchard. BSc thesis, University of Mauritius

Ratcliffe FN (1931) The flying fox (Pteropus) in Australia. Report for co-operative work conducted on behalf of the Council for Scientific Research, the New South Wales Department of Agriculture, and the Queensland Home Secretary's Department, Melbourne 
Reilly T, Slack J (1990) Cost and returns of netting low-chill stonefruit orchards. In: Slack JM (ed) Flying fox workshop proceedings. Wollongbar Agricultural Institute, Wollongbar, 22 August 1990. NSW Agriculture and Fisheries, Australia, pp 61-65

Richards GC (1990) The Spectacled flying fox, Pteropus conspicillatus, in north Queensland. 2. Diet, feeding ecology and seed dispersal. Aust Mammal 13:25-31

Richards GC, Hall LS, Parish S (2012) A natural history of Australian Bats: working the night shift. CSIRO Publishing, Melbourne

Roberts TJ (1997) The Mammals of Pakistan. Oxford University Press, Karachi

Robyn S (2007) Suivi et essai d'estimation de la population de chauve-souris frugivore (Pteropus niger) a l'Ile Maurice (monitoring and population estimate of a fruit bat [Pteropus niger] in Mauritius). Université Paul Cézanne, Memoir de Stage

Rogers J (2002) The economic and social implications of flying-fox predation on the north coast of NSW. In: Eby P, Lunney D (eds) Managing the grey-headed flying-fox as a threatened species in NSW. Royal Zoological Society of New South Wales, Mosman, NSW, pp 58-62

Rimba (2012) Special update: Terengganu protects flying foxes! http://myrimba.org/2012/02/16/ special-update-terengganu-protects-flying-foxes/. Accessed 19 May 2013

Scanlon AT, Petit S, Sternberg LDS (2013) Insectivory in Fijian flying foxes (Pteropodidae). Aust J Zool 61:342-349

Singaravelan N (2002) Foraging behaviour of fruit bats in orchards. PhD thesis, Madurai Kamaraj University

Singaravelan N, Marimuthu G (2006) Muntingia calabura — an attractive food plant of Cynopterus sphinx — deserves planting to lessen orchard damage. Acta Chiropterol 8:239-245

Singaravelan N, Marimuthu G, Racey PA (2009) Do all fruit bats deserve to be listed as vermin in the Indian Wildlife (Protection) \& Amended Acts-a critical review. Oryx 43:608-613

Simmons N (2005) Chiroptera. In: Wilson DE, Reeder DAM (eds) Mammals of the World-a taxonomic and geographic reference. Johns Hopkins University Press, Baltimore, pp $312-529$

Slack J (1990) Flying-fox damage in low-chill stone fruit orchards. In: Slack JM (ed) Flying-fox workshop proceedings. NSW Agriculture and Fisheries, Wollongbar, NSW, pp 55-60

Spitzenberger F (1979) Die Säugetierfauna Zyperns. Teil II: Chiroptera, Lagomorpha, Carnivora und Artiodactyla. Ann Nat Hist Mus 82:439-465

Srinivasulu C, Srinivasulu B (2002) Greater short-nosed fruit bat (Cynopterus sphinx) foraging and damage in vineyards in India. Acta Chiropterol 4:167-171

Stacey P (1990) Fruit industry focus-exotic fruit industry, NSW North Coast. In: Slack JM (ed) Flying fox workshop proceedings, Wollongbar Agricultural Institute. NSW Agriculture and Fisheries, Australia, pp 13-16

Stacey P (1992) To net or not to net. In: Blade K (ed) Fruit crop protection seminar. NSW National Parks and Wildlife Service, Australia, pp 20-23

Stier SC, Mildenstein TL (2005) Dietary habits of the world's largest bats: the Philippine flying foxes, Acerodon jubatus and Pteropus vampyrus lanensis. J Mammal 86:719-728

Struebig MJ, Harrison ME, Cheyne SM et al (2007) Intensive hunting of large flying foxes Pteropus vampyrus natunae in Central Kalimantan, Indonesian Borneo. Oryx 41:390-393

Swanepoel R, Leman PA, Burt FJ et al (1996) Experimental inoculation of plants and animals with Ebola virus. Emerg Infect Dis 2:321-325

Teagle S (2002) Queensland Flying-fox Consultative Committee-formation, outcomes and future strategies. In: Eby P, Lunney D (eds) Managing the grey-headed flying-fox as a threatened species in NSW. Royal Zoological Society of New South Wales, Mosman, NSW, pp 109-116

Teoh TH (2005) Logging and hunting killing bats. The Star, 5 June

Thiriet D (2010) Flying fox conservation laws, policies and practices in Australia-a case study in conserving unpopular species. Australas J Nat Resour Law Policy 13:161-194

Tidemann CR (1999) Biology and management of the grey-headed flying-fox, Pteropus poliocephalus. Acta Chiropterol 1:151-164 
Tidemann R, Kelson SI, Jamieson G (1997) Flying-fox damage to orchard fruit in Australiaincidence, extent and economic impact. Aust Biol 10:179-186

Towner JS, Amman BR, Sealy TK et al (2009) Isolation of genetically diverse Marburg viruses from Egyptian fruit bats. PLoS Path 5:e1000536

Ullio L (2002) To net or not to net that is the question! But is it the answer? In: Eby P, Lunney D (eds) Managing the grey-headed flying-fox as a threatened species in NSW. R Zool Soc New South Wales, Mosman, NSW, pp 70-76

Van Mele P (2008) The importance of ecological and socio-technological literacy in R\&D priority setting: the case of a fruit innovation system in Guinea, West Africa. Int $\mathbf{J}$ Agric Sust 6:183-194

Van Mele P, Camara K, Vaysierres JF (2009) Thieves, bats and fruit flies: local ecological knowledge on the weaver ant Oecophylla longinoda in relation to three 'invisible' intruders in orchards in Guinea. Int J Pest Manage 55:57-61

Verghese A (1998) Non-destructive control of the bat, Cynopterus sphinx Vahl (Chiroptera: Pteropodidae) in grapes (Vitis vinifera Linnaeus) in India. Int J Pest Manage 44:81-85

Vincenot CE, Koyama L, Russo D (2015) Near threatened? First report of unsuspected humandriven decline factors in the Ryukyu flying fox (Pteropus dasymallus). Mammal Biol 80:273-277

Waples K (2002) Review of the NPWS policy on the mitigation of commercial crop damage by flying-foxes. In: Eby P, Lunney D (eds) Managing the grey-headed flying-fox as a threatened species in NSW. R Zool Soc New South Wales, Mosman, NSW, pp 39-46

Weber N, Duengkae P, Fahr J et al (2015) High-resolution GPS tracking of Lyle's flying fox between temples and orchards in central Thailand. J Wildl Manage 79:957-968

Williams NSG, McDonnell MJ, Phelan GK et al (2006) Range expansion due to urbanization: increased food resources attract grey-headed flying-foxes (Pteropus poliocephalus) to Melbourne. Aust Ecol 31:190-198

Win SS, Mya KM (2015) The diet of the Indian Flying Fox Pteropus giganteus (Brünnich. 1782) (Chiroptera: Pteropodidae) in Myanmar-conflicts with local people? J Threat Taxa 7:7568-7572

Yapa WB, Kumarasinghe J, Digana PMCB et al (1999) Food preferences (three food types) of Sri Lankan short-nosed fruit bat Cynopterus sphinx (Chiroptera) in a semi-natural condition. Vidyodaya J Sci 8:109-116 